Anuario de la Facultad de Derecho. Universidad de Extremadura 35 (2019): 635-700 ISSN: 0213-988X - ISSN-e: 2695-7728

\title{
INFORME ANUAL SOBRE LA SITUACIÓN JURÍDICO- PÚBLICA DE LA COMUNIDAD AUTÓNOMA DE EXTREMADURA EN 2019
}

\author{
ANNUAL REPORT ON THE SITUATION OF THE \\ AUTONOMOUS COMMUNITY OF EXTREMADURA DURING \\ 2019
}

\author{
VICENTE ÁLVAREZ GARCÍA \\ Universidad de Extremadura \\ FLOR ARIAS APARICIO \\ Universidad de Extremadura \\ ENRIQUE HERNÁNDEZ DÍEZ \\ Universidad de Extremadura
}

\section{RESUMEN}

El Informe de la Comunidad Autónoma de Extremadura constituye una crónica de la situación jurídica y político-institucional de la región en el año 2019. Las cuestiones principales que se analizan en este Informe son: en primer lugar, las principales circunstancias que rodean la actividad político-institucional de la región; en segundo lugar, las líneas centrales de su actividad normativa -legislativa y reglamentaria-; $y$, en tercer lugar, sus relaciones interadministrativas y conflictuales -esencialmente con la Administración General del Estado-. Se cierra el Informe con el examen de alguno de los problemas socio-económicos que padece la región. En este año se ha puesto el acento en la deficitaria red extremeña de infraestructuras. 
Palabras clave: Derecho administrativo, Comunidad Autónoma de Extremadura, Actividad legislativa, Actividad reglamentaria, Actividad político-institucional, conflictividad Estado-Comunidad Autónoma, jurisprudencia constitucional.

ABSTRACT

The Report of the Autonomous Community of Extremadura is a chronicle of the legal and political-institutional situation of the region in 2019. The main issues analysed in this report are: firstly, the main circumstances surrounding the region's political-institutional activity; secondly, the main lines of its legislative and regulatory activity; and thirdly, its inter-administrative and conflictive relations -essentially with the General State Administration. The Report closes with an examination of some of the socio-economic problems suffered by the region. This year the emphasis has been placed on the deficient Extremaduran infrastructure network.

Keywords: Administrative law, Autonomous Community of Extremadura, Legislative activity, Regulatory activity, political-institutional activity, conflict between the State and the Autonomous Community, constitutional jurisprudence.

Sumario: 1. Consideraciones preliminares. 2. Introducción a las grandes líneas rectoras de la actividad político-institucional y jurídica autonómica. 3. Una crónica sobre la actividad político-institucional regional: 3.1. Los resultados de las citas electorales en Extremadura; 3.2. La formación de la nueva Junta de Extremadura. 4. La actividad normativa en Extremadura: 4.1. La actividad legislativa parlamentaria y gubernamental; 4.2. La actividad reglamentaria y administrativa de la Junta de Extremadura y de su Presidente. 5. La conflictividad entre la Comunidad Autónoma de Extremadura y la Administración General del Estado: 5.1. Las controversias formuladas en el seno de la Comisión Bilateral de Cooperación Administración General del Estado-Comunidad Autónoma de Extremadura; 5.2. La jurisprudencia constitucional con específica relevancia para la Comunidad Autónoma de Extremadura. 6. A propósito de algún problema crónico en la región: la deficitaria red extremeña de infraestructuras: 6.1. El caos ferroviario; 6.2. Las carencias de la red de carreteras; 6.3. Las deficiencias en el tráfico aéreo; 6.4. A modo de breve conclusión. 
Informe anual sobre la situación jurídico-pública de la Comunidad Autónoma de Extremadura 637

\section{CONSIDERACIONES PRELIMINARES}

Comienzo en este número del Anuario de la Facultad de Derecho de la Universidad de Extremadura la publicación de un Informe Anual sobre el estado de nuestra Comunidad Autónoma.

Son numerosísimas, ciertamente, las revistas jurídicas que existen dentro de las fronteras patrias. Resulta difícil que una publicación de la naturaleza de este Anuario pueda competir con las mejores de entre ellas, pero sí que creo que debe cumplir una función primaria: servir de cauce de conocimiento, al menos, de los desarrollos jurídicos y político-institucionales que se desarrollen dentro de nuestra Región.

Con esta finalidad tanto mi equipo de colaboradores como yo mismo pretendemos elaborar anualmente un Informe (que, viniendo del mundo académico, debe ser necesariamente crítico, a la vez que constructivo), sobre los acontecimientos más destacados que ejercicio tras ejercicio sucedan en Extremadura.

Contamos ya con una cierta experiencia en estos quehaceres, puesto que en esta última década hemos venido relatando diversas parcelas de la vida jurídica regional dentro de tres obras señeras dentro del Derecho hispano: en primer término, el Informe Comunidades Autónomas, dirigido a lo largo de los años por los profesores Eliseo Aja, Joaquín Tornos, Javier García Roca y José Antonio Montilla; en segundo término, el $O b$ servatorio de Políticas Ambientales, encabezado por el profesor Fernando López Ramón; y en tercer término, el Anuario de Derecho de Fundaciones, con los profesores Santiago Muñoz Machado y José Luis Piñar Mañas al frente.

La columna vertebral de la que pretendo (pretendemos) dotar al Informe Anual sobre Extremadura es la seguida por las crónicas de cada una de las Administraciones Territoriales dentro del Informe Comunidades Autónomas (que, con una extensión obligadamente limitada por sus características, destacan: en primer lugar, las principales 
circunstancias que rodean la actividad político-institucional de cada región; en segundo lugar, las líneas centrales de su actividad normativa legislativa y reglamentaria-; y, en tercer lugar, sus relaciones interadministrativas y conflictuales -esencialmente con la Administración General del Estado-), pero enriquecido a partir del siguiente número de este Anuario con las aportaciones medioambientales y del tercer sector con las que dos de mis colaboradores, Flor Arias Aparicio y Enrique Hernández Diez, están ya tan familiarizados, y con las de aquellas otras personas, procedentes tanto del mundo de la Universidad como del ámbito institucional o del sector privado, que quieran apoyar el proyecto que con estas páginas inicio (iniciamos).

Decía que el estudio central de este trabajo estará inspirado en los próximos años en el Informe Comunidades Autónomas, que precisamente en el año 2020 cumple su trigésimo aniversario, y del que en estos primeros párrafos quiero de manera muy personal hacerme eco, a través de la siguiente breve, pero más que merecida, reseña.

Resulta de Justicia recordar, en este orden de ideas, que la Fundación Carles Pi i Sunyer d'Estudis Autònomics i Locals (sustituida más tarde por el Instituto de Derecho Público de Barcelona -IDP-)- inició en 1990 la edición anual del Informe sobre las Comunidades Autóno$\mathrm{mas}^{2}$, primero con el nombre Informe Pi i Sunyer sobre Comunidades Autónomas, y después con el más conciso título de Informe Comunidades Autónomas. En dicho monumental trabajo, que con su maestría característica han dirigido a lo largo del tiempo los citados profesores Aja

\footnotetext{
1 El IDP, según se define en su página web, "es un centro universitario de análisis e investigación especializado en diferentes ámbitos del Derecho Público, especialmente Derecho Constitucional, Administrativo y Unión Europea, así como en otras disciplinas afines". El funcionamiento de este centro universitario "se inició en 1989, como fruto de la colaboración de profesores en la redacción de estudios académicos, se formalizó en 1993, se integró al Parque Científico de Barcelona en 2001 y ha sido reconocido como Observatorio de la Universidad de Barcelona en 2010" (http://idpbarce lona.ub.edu).

2 Téngase en cuenta que el primer Informe se publicó en 1990 con los estudios relativos al funcionamiento del Estado Autonómico durante el año 1989. Es justo recordar, en todo caso, que con anterioridad a estas fechas (en concreto, en 1988) se publicó por la editorial Civitas el trabajo "Informe sobre las Autonomías", dirigido por J. Tornos, E. Aja, T. Font, J. M. Perulles y E. Albertí, y que contó con la colaboración de cerca de otras dos decenas de autores.
} 
y Tornos (a los que posteriormente se fueron añadiendo los también referidos García Roca y Montilla), se ha analizado durante tres décadas la situación de nuestro Estado Autonómico. En todos y cada uno de estos años se ha procedido a un riguroso examen, por una parte, de las actividades jurídicas y político-institucionales de las diecisiete Comunidades Autónomas y de las dos Ciudades Autónomas de Ceuta y de Melilla, una a una; así como, y por otra, del contexto estatal y europeo en el que se ha enmarcado su funcionamiento.

Este ambicioso proyecto ha permitido descubrir anualidad tras anualidad los logros en la construcción de nuestro modelo de Estado, pero también las fallas que han rodeado y siguen rodeando su diseño. Fallas que, en el marco de la crisis económica, política e institucional que hemos padecido -y lamentablemente seguimos sufriendo bajo viejas y nuevas formas a día de hoy-, ponen en cuestión su propia supervivencia, al menos tal y como lo hemos venido conociendo desde su nacimiento.

El proyecto originario de la Fundación Pi i Sunyer (y después del IDP) sufrió una mutación con un obligado paréntesis en la edición del texto de las crónicas autonómicas en el Informe en el año 2012 -por los problemas ligados a su financiación-, y con la paralela constitución del Foro de las Autonomías, cuya primera gran manifestación externa tuvo lugar en el Senado el día 25 de junio de 2012. En los años siguientes, el trabajo del IDP se redobló, puesto que, por un lado, se ha venido celebrando en la Cámara Alta anualmente -desde entonces, y hasta el día de hoy- el referido Foro de las Autonomías (que ha llegado a su octava edición durante la primavera de 2019); y, por otro, volvió a publicarse nuevamente el Informe completo desde el año 2014 (con las crónicas autonómicas correspondientes al ejercicio de 2013), si bien con una extensión considerablemente más reducida espacialmente de sus aportaciones (recuperándose el texto de las crónicas perdidas de la anualidad de 2012 con el esfuerzo de los colaboradores regionales del Informe en el año 2018 -que ese año escribieron retrospectivamente, junto con el trabajo correspondiente a esa anualidad, el relato que faltaba del meritado ejercicio 2012-). 
Con estas vicisitudes, lo cierto es que las crónicas que, desde 1989, se han realizado sobre todas y cada una de las grandes piezas territoriales que integran España han permitido todos los años saber cuál era la situación jurídica y político-institucional de cada Comunidad Autónoma en el momento de elaborarse, y con el paso del tiempo han ido posibilitando y, naturalmente siguen facilitando a día de hoy, la reconstrucción de cómo ha evolucionado cada territorio regional en los seis últimos lustros. O de otra manera si se quiere, permiten comprender la historia reciente de cada Comunidad Autónoma. Y, por supuesto, a través de esas crónicas "territoriales", pero también mediante los estudios globales de naturaleza transversal para el conjunto del Estado que las han acompañado, se posibilita la explicación y la comprensión del devenir de nuestro sistema de organización territorial.

Bajo esta perspectiva global, la labor de relatar, en el marco del "Informe Comunidades Autónomas” (y, posteriormente, también en el Foro de las Autonomías), cómo ha ido evolucionando la Comunidad Autónoma de Extremadura año a año ha correspondido a distintas personalidades -extremeñas de nacimiento o, al menos, de espíritu- tanto del mundo académico como del institucional, desde que, con su ágil, precisa y preciosista pluma, Ignacio Sánchez Amor escribiese allá por el año 1990 su primera crónica sobre la situación jurídica y político-institucional de Extremadura en el anterior año 1989, hasta la crónica relativa a 2018, cuya redacción durante los primeros días de 2019 corrió a cargo de quien ahora escribe estas líneas. En la confección de esta particular historia jurídica y político-institucional de Extremadura que hoy conforma el conjunto de todas esas crónicas anuales han participado (además, naturalmente, de Ignacio Sánchez Amor y de yo mismo) personas de la categoría de Pablo Pérez Tremps, María Antonia Trujillo Rincón, José Ignacio Navarro Méndez, Francisco Javier Donaire Villa, José Antonio Montilla Martos y Marcos Criado de Diego 3 . Y creo justo, por último,

3 Ignacio Sánchez Amor es el autor de las crónicas iniciales, esto es, las correspondientes a los años 1989, 1990 y 1991. Pablo Pérez Tremps suscribe en solitario las referentes a los ejercicios 1992, 1993, 
efectuar también un recordatorio, siquiera breve y genérico, a todas las personas que de una u otra forma han colaborado con los referidos autores durante el proceso de elaboración de cada una de las crónicas anuales; y ya de una manera más particular dirijo mi agradecimiento desde estas líneas a todos mis colaboradores a lo largo de estos años: Maite Pérez Vega, Felipe Jover, Javier Ciriero, Adrián Calderón, Patricia Doncel, Enrique Hernández, Flor Arias Aparicio y Daniel Vaquero.

Fijadas, estimado lector, las pretensiones iniciáticas de este trabajo y sus objetivos futuros, y finalizado el merecidísimo homenaje a la obra Informe Comunidades Autónomas y a las muchísimas personas que hay detrás de él, comienzo (comenzamos) sin más dilación este Informe sobre Extremadura correspondiente al año 2019.

\section{INTRODUCCIÓN A LAS GRANDES LÍNEAS RECTORAS DE LA AC- TIVIDAD POLÍTICO-INSTITUCIONAL Y JURÍDICA AUTONÓMICA}

El año 2019 ha traído consigo el paso de la IX a la X Legislatura autonómica, tras las elecciones a la Asamblea de Extremadura que acontecieron durante el mes de mayo.

Esta anualidad ha tenido un marcado carácter electoral, pues, junto a los comicios regionales, los ciudadanos han sido llamados a otras cuatro citas electorales: dos generales, una para el nivel municipal y otra para el Parlamento Europeo. Todas estas convocatorias de los meses de abril, mayo y noviembre han tenido importantes mayorías para el Partido Socialista Obrero Español (PSOE), que han alcanzado su culmen en

\footnotetext{
1994, 1995, 1996 y 1997. La relativa a 1998 está escrita tanto por el citado Pablo Pérez Tremps como por María Antonia Trujillo Rincón, que es, además, la autora única de la correspondiente a 1999. Las crónicas referidas a los años 2000 y 2001 están firmadas por Pablo Pérez Tremps y por José Ignacio Navarro Méndez. Francisco Javier Donaire Villa es el autor de las relativas a los ejercicios 2002, 2003 y 2004. Las crónicas de los años 2005, 2006 y 2007 están escritas por José Antonio Montilla Martos, mientras que las de 2008, 2009 y 2010 lo han sido por Marcos Criado de Diego. Por último, el autor del presente trabajo lo es también de las crónicas correspondientes a los años comprendidos entre 2011 y 2018.
} 
las elecciones a la Asamblea de Extremadura, saldadas con una holgada mayoría absoluta de este grupo político.

A resultas de esta abrumadora victoria a nivel regional, el máximo dirigente territorial de la referida formación política, D. Guillermo Fernández Vara, fue investido por una mayoría absoluta de la Cámara Legislativa como Presidente autonómico, revalidando de esta manera el mandato que había venido ejerciendo ya durante los cuatro años anteriores, apoyado entonces en una mayoría simple del grupo socialista.

La nueva configuración parlamentaria ha servido para que el Presidente formase en el comienzo mismo del mes de julio un nuevo Gobierno regional con todos sus anteriores Consejeros, a los que se han sumado dos nuevos nombres. La actual estructura gubernamental ha pasado de este modo a contar con nueve miembros, dos de los cuales ostentan, asimismo, sendas vicepresidencias.

Además del mayoritario grupo socialista, que cuenta con treinta y cuatro diputados en la Asamblea de Extremadura (de los sesenta y cinco que componen legalmente este órgano), están también representados en el parlamento regional el Partido Popular (PP) -con veinte escaños-, Ciudadanos -con siete- y Podemos -con cuatro-. No lo está, sin embargo, Vox al no haber superado la barrera del $5 \%$ en ninguna de las dos circunscripciones existentes para las elecciones regionales, constituidas por las provincias de Cáceres y de Badajoz. A pesar de esta situación, lo cierto es que, tras las elecciones generales de noviembre de 2019, esta última formación ha pasado a convertirse en la tercera fuerza política a nivel regional tanto en número y porcentaje de votos como a nivel de escaños en el Congreso de los Diputados (con dos representantes), únicamente superada por el PSOE, con sus cinco diputados, y por el PP, que ha logrado tres. En esta lista, Podemos ocupa la cuarta posición, mientras que Ciudadanos ha caído hasta la quinta, pero careciendo ambas formaciones de una representación en Madrid que haya sido directamente mandatada por los votantes extremeños. 
Desde la perspectiva de la actividad normativa, este año de encrucijada entre Legislaturas se ha cerrado con la aprobación de un total de trece leyes formales, entre las cuales no se encuentra la Ley de presupuestos generales autonómicos para 2020. Éste es, en efecto, el quinto ejercicio consecutivo en el que se produce esta circunstancia, pero esta vez no por causas realmente imputables al Ejecutivo regional o a la Asamblea de Extremadura, puesto que el PSOE posee en la misma una mayoría más que suficiente para tal fin, sino por la inestabilidad que ha existido a nivel estatal con un Gobierno en funciones durante la mayor parte del año, que no ha logrado el apoyo necesario para sacar adelante unos Presupuestos Generales del Estado que sirviesen de marco jurídico y económico para las cuentas públicas autonómicas. Estas trece normas legales parlamentarias referidas, que se han dictado en su gran mayoría en los meses finales de la IX Legislatura (un total de once -algunas de ellas con una significativa importancia desde las perspectivas social y del régimen jurídico de las Administraciones públicas-), se han visto, asimismo, acompañadas de un decreto-ley gubernamental en materia de juego aprobado en los primeros días del mes de febrero. Entre las dos leyes formales adoptadas en los meses iniciales de la actual X Legislatura destaca, por su significación política, la destinada a la supresión del límite de mandatos para el acceso a la Presidencia de la Junta de Extremadura.

La labor reglamentaria y, sobre todo, administrativa de esta última Alta Magistratura regional, que se ha materializado en ambos supuestos bajo la forma del Decreto del Presidente, ha sido considerablemente elevada, tal y como resulta propio de un año de comicios autonómicos, destacando por su número los destinados al cese y al nombramiento de los Consejeros de la Junta de Extremadura y, por su importancia desde una perspectiva material, los relativos a la convocatoria de elecciones a la Asamblea de Extremadura y de la sesión constitutiva de esta cámara legislativa, así como el destinado a la reordenación de los departamentos llamados a conformar el nuevo gobierno autonómico. Por lo que respecta 
a la actividad de la Junta de Extremadura, su número de decretos es muy inferior al de los años de inicio de las VIII y IX Legislatura (esto es, 2011 y 2015), e incluso algo más reducido al de los años inmediatamente precedentes (2016, 2017 y 2018). En todo caso, la mayor parte de las decisiones gubernamentales tienen una naturaleza de actos singulares, puesto que han sido el cauce formal para acordar el cese y el nombramiento de los altos cargos de la Administración extremeña. Los decretos consagrados a la actividad de fomento (subvenciones y otros tipos de ayudas), que, año tras año, suelen constituir la temática estrella de la actividad gubernamental en nuestra región, han pasado este ejercicio, sin embargo, a ocupar el segundo lugar desde un punto de vista cuantitativo, aunque a gran distancia de los centrados en la referida cuestión de la designación y cese de los altos rectores de la Administración extremeña.

En el plano de las relaciones entre la Comunidad Autónoma extremeña y la Administración General del Estado destaca la gran actividad que esta anualidad ha tenido la Comisión Bilateral de Cooperación, que ha alcanzado hasta trece acuerdos, bien para abrir negociaciones sobre normas legales autonómicas cuya constitucionalidad era puesta en entredicho por el Gobierno estatal o bien para la adopción de una solución consensuada que evitase su impugnación ante nuestro Tribunal Constitucional. En este contexto, han sido dos los pronunciamientos de este Alto Tribunal durante este ejercicio en torno al reparto competencial entre el Estado y nuestra Comunidad Autónoma. Pero estas decisiones constitucionales han venido propiciadas, no por un recurso de inconstitucionalidad o por un conflicto de competencias promovido desde la Administración General de Estado, sino por sendas cuestiones de inconstitucionalidad elevadas por la Sala de lo Contencioso-Administrativo del Tribunal Superior de Justicia de Extremadura, y que se enmarcan, desde un punto de vista material, en el viejo conflicto de naturaleza urbanística que desde hace más de una década afecta a la isla del embalse de Valdecañas, ubicada en el río Tajo. Los pronunciamientos de nuestro Tribunal Constitucional se han cerrado esta anualidad con una tercera Sentencia 
cuyo origen se encuentra en un recurso de amparo parlamentario promovido por el único diputado no adscrito durante la pasada IX Legislatura en la Asamblea de Extremadura. Esta resolución, que es ciertamente novedosa e importante desde la perspectiva del Derecho parlamentario patrio, sirve precisamente para confirmar que la condición de diputado no adscrito resulta plenamente compatible con el derecho fundamental al acceso, a la permanencia y al ejercicio de los cargos públicos (art. 23 $\mathrm{CE}$ ), así como para perfilar el contenido esencial de las facultades representativas de que goza esta categoría de diputados.

Por último, creo que merece la pena subrayar en este lugar que nuestra Comunidad Autónoma sigue careciendo de unas infraestructuras ferroviarias equiparables a las del resto del Estado. Las inmensas deficiencias del "tren extremeño" quedaron de manifiesto con las graves averías que sufrieron una multiplicidad de trenes en los primeros días del presente año y que, durante varias jornadas, fueron noticia de portada de la prensa nacional y de los informativos televisivos y radiofónicos. En todo caso, el nivel de reivindicación social sobre esta cuestión se ha ido diluyendo a lo largo de los meses. No son ya, en el momento de escribir estas páginas, noticias destacadas los incidentes ferroviarios, quizá porque puedan haber disminuido y porque, además, el Gobierno regional parezca satisfecho con los avances en la construcción de las infraestructuras. La disminución de las reclamaciones sociales ha llegado hasta tal punto que la manifestación reivindicativa que, gracias al apoyo de todas las instituciones extremeñas, de los partidos políticos más significativos de la región y de amplísimos colectivos sociales, se convocaba cada 18 de noviembre desde 2017, y que contaba con grandísimo número de asistentes, este año ha dejado de estar en el candelero de la actualidad autonómica para formar parte de una historia cada vez más lejana y difusa. 


\section{UNA CRÓNICA SOBRE LA ACTIVIDAD POLÍTICO-INSTITUCIO- NAL REGIONAL}

\subsection{LOS RESULTADOS DE LAS CITAS ELECTORALES EN EXTREMADURA}

Las numerosas citas electorales que han caracterizado la actividad político-institucional durante este año 2019 han abarcado todos los niveles territoriales, desde el europeo hasta el municipal, pasando por el estatal y el autonómico. Es precisamente este ámbito el que centrará la mayor parte de nuestra atención, dado que es el que sirve para marcar el paso de la IX a la X Legislatura regional.

\subsubsection{Las elecciones europeas de 26 de mayo}

Aunque en este tipo de comicios la circunscripción electoral es única para el conjunto del Reino de España, los datos desglosados correspondientes a la Comunidad Autónoma de Extremadura arrojaron una absoluta mayoría del voto para el Partido Socialista Obrero Español, seguido a enorme distancia, y por este orden, por el Partido Popular, Ciudadanos, Podemos-Izquierda Unida y Vox.

En las anteriores elecciones europeas de 2014, el PSOE también había resultado victorioso con el 38,73\% de los votos, que se han incrementado hasta el 45,97\% (con más de 277 mil votos) durante el proceso electoral del presente ejercicio. El PP, que había quedado en segundo lugar en 2014, continúa en esa misma posición, pero con un importante descenso en el porcentaje de votos, pues ha pasado del 35,55\% (correspondiente a algo más de 155 mil votos) al 25,75\%. El aumento más espectacular en número de votantes correspondió a Ciudadanos que ascendió de menos del 1\% hasta el 11,25\% (con casi 68 mil sufragios). Los partidarios de Podemos-Izquierda Unida lograron el 6,74\% (unos 40.600 votantes) y los de Vox el 5,64\% (con poco más de 34 mil apoyos).

Con muy pequeñas variaciones en los porcentajes de voto, esta misma ordenación entre partidos se verificó tanto en la provincia de Cáceres como en la de Badajoz. 
3.1.2. La doble cita electoral para la conformación de las Cortes Generales

El 28 de abril se celebraron las primeras elecciones generales de este año 2019, volviendo a repetirse el 10 de noviembre, después de que no se pudiese alcanzar una mayoría parlamentaria suficiente para lograr la investidura de un Presidente del Gobierno que permitiese la conformación de un nuevo equipo gubernamental ni en el mes de julio ni en el de septiembre.

a. Las elecciones generales del 28 de abril

Los comicios de abril supusieron una rotunda victoria del PSOE en el conjunto del territorio extremeño con una participación superior al $76 \%$ del censo electoral. Nuestra región reparte diez escaños para el Congreso de los Diputados, de los cuales la mitad fueron a parar directamente al referido Partido Socialista, mientras que los cinco restantes se repartieron entre el PP (con dos), Ciudadanos (también con dos) y el último fue para Vox. Comparando estos resultados con las cifras de las elecciones generales de 2016, puede constatarse que han supuesto el aumento en un escaño por parte del PSOE, la pérdida de tres por el PP, la ganancia de sus dos diputados por parte de Ciudadanos, al igual que sucede con el escaño de Vox. Podemos, sin embargo, pierde el diputado que había logrado en el año 2016 para el Congreso por la provincia pacense.

En efecto, el PSOE logró con sus casi 250 mil votantes (que se corresponden con un porcentaje de voto del $38 \%$ ) un total de cinco diputados nacionales a nivel autonómico, que resultan de la suma de dos diputados por la provincia de Cáceres (más de 92.600 votantes -con un porcentaje del $37,4 \%$ de la cifra total de participación-) y de tres por la provincia de Badajoz (con casi 156.000 votantes -lo que equivale porcentualmente al 38,49\%-).

Los dos diputados del PP, que son fruto de sus más de 140 mil sufragios (un 21,4\% del total), provienen uno de la circunscripción cacereña 
(con unos 57 mil votos -el 23,03\%-) y otro de la pacense (con casi 83.200 apoyos -un 20,41\%-).

Este mismo resultado en escaños (y con idéntico reparto provincial) alcanzó Ciudadanos, aunque su número de votantes fue sensiblemente inferior a los del partido azul (unos 117.800 sufragios -poco menos del 18\%-). En la provincia de Cáceres su diputado logró casi 43.000 sufragios (algo más del 17\%) y unos 75.500 en la de Badajoz (el 18,50\%).

El diputado de Vox fue elegido por la provincia de Badajoz. Este partido contó con más de 70.600 votantes a nivel regional (el 10,77\%), con unos 25.800 en Cáceres (el 10,42\%) y unos 44.800 en la de Badajoz (casi el $11 \%)$.

Podemos perdió la representación parlamentaria que había obtenido por la provincia de Badajoz. Sus votos en el territorio extremeño alcanzaron una cifra superior a los 62.200 (casi un 9,50\%), que se corresponden con unos 24.125 sufragios por la provincia de Cáceres (el 9,74\%) y unos 38.100 por la circunscripción pacense (el 9,35\%).

Extremadura cuenta con diez representantes en el Senado, provenientes de la suma de cuatro por cada provincia y de dos senadores autonómicos designados por el Parlamento regional. El PSOE obtuvo tres senadores en cada una de las provincias (un total de seis, por tanto), al que debe añadirse, además, uno de los senadores autonómicos. Los otros tres senadores correspondieron al PP: uno por cada provincia y otro (que fue D. José Antonio Monago, Expresidente de la Junta de Extremadura y líder regional del PP) por designación de la Asamblea de Extremadura.

\section{b. Las elecciones generales del 10 de noviembre}

Las elecciones generales del 10 de noviembre sirvieron para ratificar la aplastante victoria socialista en el conjunto de los comicios celebrados en nuestra Región durante la presente anualidad, y, en particular, la conseguida en la anterior convocatoria de abril para la designación de los diputados y senadores representantes de nuestra tierra en las dos 
cámaras que conforman las Cortes Generales. Es cierto, eso sí, que, a nivel regional, el apoyo al PSOE ha disminuido entre unos y otros comicios generales en unos 23 mil votantes (pero manteniéndose su porcentaje de voto en ambos casos en torno al 38\%). Además de la confirmación del triunfo del PSOE, revalidando sus cinco escaños en el Congreso de los Diputados, los datos electorales más destacados en los comicios de noviembre han sido, en mi opinión, los cuatro siguientes: en primer término, la debacle de Ciudadanos, que ha perdido sus dos escaños, pasando de tercera a quinta fuerza política regional; en segundo término, la ganancia de uno de esos escaños por parte del PP, que, de esta manera, ha pasado a contar con tres diputados; en tercer término, el aumento por parte de Vox de otro escaño, hasta alcanzar dos miembros en la Cámara Alta, convirtiéndose de este modo en el tercer partido extremeño; y en cuarto término, la ausencia de representación de Podemos a nivel parlamentario estatal, si bien es cierto que esta formación morada ha superado en votos a la naranja, lo que la sitúa como cuarto partido regional en apoyo popular. En todo caso, estos resultados electorales se han visto un tanto empañados por la caída de la participación en unos siete puntos, dado que acudió a votar en noviembre poco más del 69\% de la ciudadanía con derecho a voto.

Desagregando estos resultados, el PSOE obtuvo en el conjunto regional algo más de 226.700 votos (equivalentes al 38,34\% de los votos) con los que revalidó sus cinco diputados, y que constituyen la suma de los dos escaños obtenidos por la circunscripción provincial cacereña (con más de 84.750 sufragios -que suponen un porcentaje del 38,15\% del total de los votos-) y de otros tres por la provincia pacense (con casi 142 mil votos -correspondientes porcentualmente al 38,46\%-).

El PP ha aumentado su representación en el Congreso al lograr tres escaños, gracias a sus casi 154 mil apoyos (que equivalen al 26,03\% de los sufragios). Este partido mantiene, en efecto, su diputado por la provincia de Cáceres (con sus más de 61.350 votos -un 27,62\%-), pero 
incrementa su representación hasta los dos diputados en la circunscripción pacense (con casi 92.600 votos -el 25,08-).

Vox se convierte en la tercera fuerza política regional (desplazando de este lugar a Ciudadanos) con la obtención de dos escaños, fruto de sus más de 99.500 votantes (que suponen el 16,83\%). Estos dos escaños provienen de la suma del diputado logrado por vez primera en la circunscripción cacereña (con más de 35.650 sufragios -el 16,05\%-) y del revalidado en la provincia pacense (con casi 63.900 apoyos -un 17,31\%-).

Podemos no logra ningún escaño, como ya sucedió en las elecciones de abril, si bien es cierto que, a diferencia de entonces, alcanza la cuarta posición en número de votos tanto a nivel regional con casi 53.700 (el 9,08\%), como en cada una de las dos provincias: en Cáceres obtuvo casi 19.900 apoyos (el 8,95\%) y en Badajoz cerca del 33.800 (un 9,15\%).

Ciudadanos, al igual que ha sucedido a lo largo y ancho de todo el país, ha sufrido un desplome extraordinario que, además de hacerle perder sus dos escaños, le relega a la quinta fuerza política, con unos 44.850 apoyos a nivel regional (equivalentes al 7,58\%), que provienen de la suma de los más de $\mathbf{1 5 . 4 0 0}$ votos por la circunscripción cacereña (el $6,95 \%$ ) y de otros 29.400 sufragios por la provincia pacense (un 7,97\%).

La representación extremeña en el Senado se mantiene en noviembre en los mismos términos que en las elecciones de abril, dado que, de los ocho senadores elegidos directamente por el cuerpo electoral regional, seis siguen correspondiendo al PSOE (tres por cada una de las dos provincias) y los dos restantes permanecen en manos del PP (uno por cada circunscripción provincial).

3.1.3. Las elecciones autonómicas de 26 de mayo de 2019 y la constitución de la nueva Asamblea de Extremadura

La IX Legislatura de la Asamblea de Extremadura se cerró con la presencia de cuatro grupos parlamentarios y la existencia de un diputado no adscrito, que había abandonado el año 2018 el PP para integrarse en Vox. 
El reparto de escaños entre los partidos políticos con representación en el Parlamento regional mostraba que el grupo socialista contaba con una mayoría simple de treinta diputados que servía de soporte a un gobierno monocolor encabezado por el Presidente D. Guillermo Fernández Vara. El PP, que al comienzo de la Legislatura contaba con veintiocho escaños, la cerró con veintisiete tras la referida fuga. El grupo parlamentario Podemos-Extremadura estaba conformado por seis diputados, mientras que la única representante de Ciudadanos se integraba en el grupo parlamentario mixto.

Las elecciones regionales de este año, que han servido para abrir la $\mathrm{X}$ Legislatura, han reforzado de manera muy considerable la mayoría con la que ya contaba el PSOE en la Asamblea de Extremadura desde el año 2015. Este partido político, en efecto, ha visto aumentar su representación parlamentaria hasta los treinta y cuatro escaños que suponen una holgada mayoría absoluta en el seno de la Cámara Legislativa (Gráfico 1). Con una participación del 69,48\% del censo electoral regional (inferior en torno a un 3,8\% con respecto a las elecciones autonómicas de 2015), esta mayoría parlamentaria resulta de latraducción en escaños de 287.619 sufragios de los votantes extremeños (un 46,14\% en términos porcentuales) (Gráfico 2). El PSOE ganó en las dos circunscripciones provinciales: mientras que obtuvo catorce escaños en Cáceres (con más de 104 mil sufragios), fueron veinte los logrados en Badajoz (superando los 183 mil votos) (Gráficos 3 y 4). La mayoría absoluta así lograda sirvió 
para investir como Presidente de la Junta para un tercer mandato -y segundo consecutivo- al líder socialista D. Guillermo Fernández Vara.

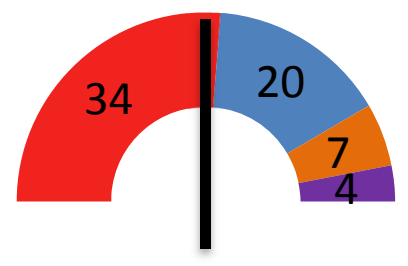

Mayoría Absoluta: 33

- PSOE (个4)

$\square P P(\downarrow 8)$

Cs (个6)

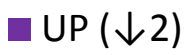

\section{Total de escaños: 65}

Gráfico 1: Elecciones autonómicas de 2019 en Extremadura*

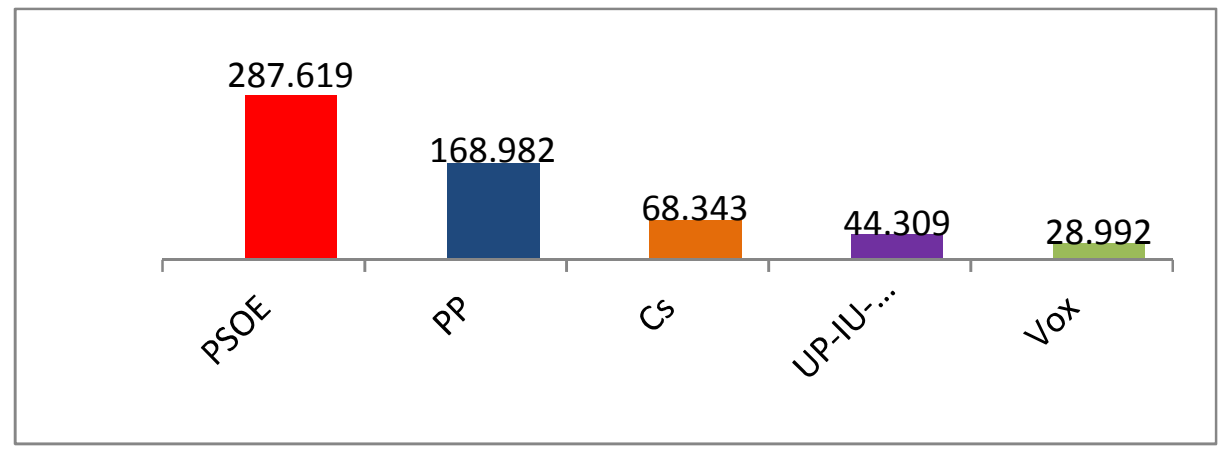

Gráfico 2: Número de votos en las elecciones autonómicas de Extremadura de 2019* 


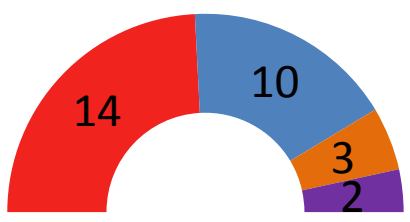

PSOE (个2)

$\mathrm{PP}(\downarrow 3)$

$\operatorname{Cs}(\uparrow 2)$

Total de escaños: 29

UP $(\downarrow 1)$

Gráfico 3: Elecciones autonómicas en la circunscripción de Cáceres*

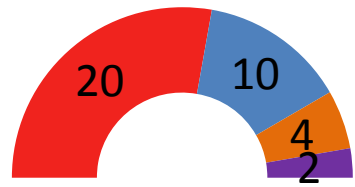

Total de Escaños: 36
PSOE (个2)

PP $(\downarrow 5)$

Cs (个4)

U UP ( $\downarrow 1)$

Gráfico 4: Elecciones Autonómicas en la circunscripción de Badajoz*

*Fuente: Elaboración por Daniel Vaquero a partir de los datos publicados en el Diario Oficial de Extremadura, núm. 110, de 10 de junio de 2019.

El PP ha visto muy considerablemente reducida su presencia en la Asamblea autonómica, puesto que se ha quedado con tan sólo veinte escaños tras lograr el apoyo de 168.982 extremeños (un 27,11\% del total), que son fruto de la suma de sus diez diputados por la provincia cacereña (alcanzados por sus 69.906 apoyos en esta circunscripción) y de los otros diez logrados en la provincia pacense (con 99.076 sufragios). Al frente de estas dos decenas de diputados en el Parlamento autonómico se sigue manteniendo el líder popular y expresidente regional D. José Antonio Monago. 


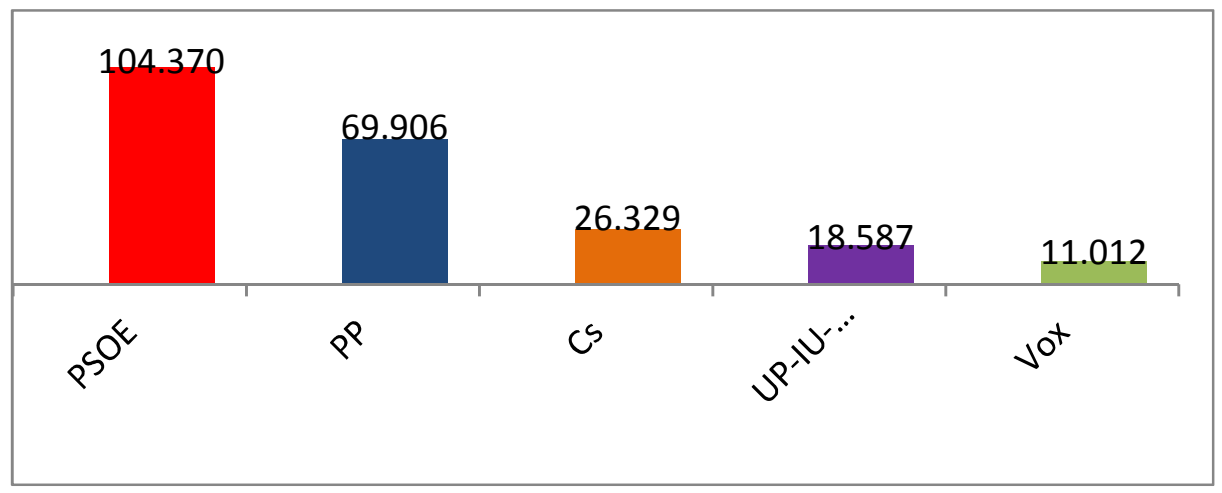

Gráfico 5: Número de votos en la circunscripción de Cáceres*

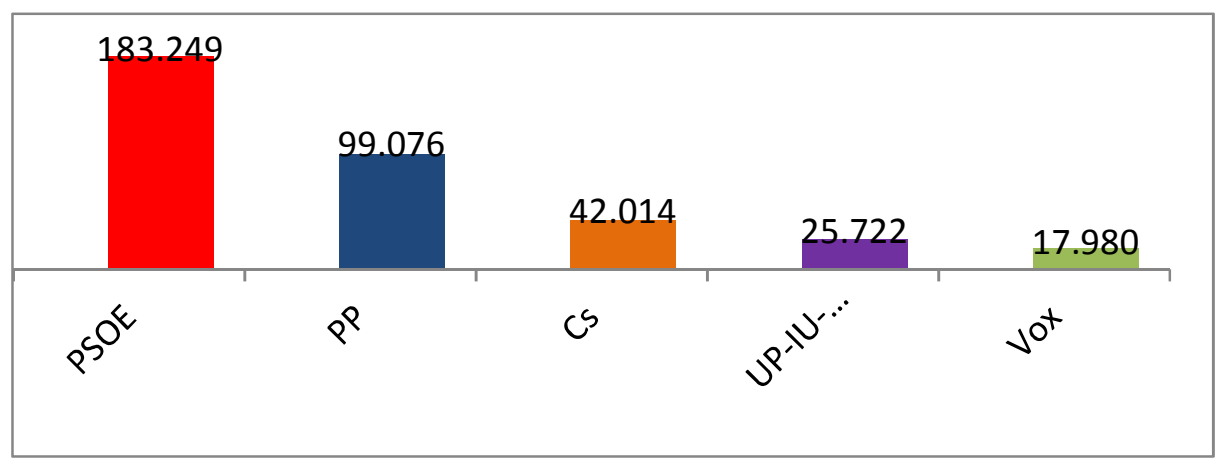

Gráfico 6: Número de votos en la circunscripción de Badajoz**

*Fuente: Elaboración por Daniel Vaquero a partir de los datos publicados en el Diario Oficial de Extremadura, núm. 110, de 10 de junio de 2019.

Ciudadanos se ha consagrado como la tercera fuerza política extremeña con sus siete diputados, tras alcanzar el soporte de 68.343 extremeños (que suponen el 10,96\% de los votos regionales). Estos escaños totales son el resultado de la agregación de los tres logrados en Cáceres (con 26.329 sufragios) y de los cuatro alcanzados en Badajoz (con 42.014 votos). El máximo dirigente regional de este partido es su diputado autonómico D. Cayetano Polo.

La coalición Podemos-IU-Extremeños-Equo ha quedado como última fuerza política con representación en la Cámara autonómica con 
cuatro escaños (con unos 44 mil apoyos en el conjunto regional), fruto de la adición de sus dos escaños por Cáceres (gracias a sus 18.587 votos) y de otros dos por Badajoz (con 25.722 sufragios). La portavocía de este grupo en la Asamblea de Extremadura está en manos de su cabeza de lista $\mathrm{D}^{\mathrm{a}}$ Irene de Miguel.

Vox quedó fuera del Parlamento autonómico, a pesar de haber obtenido en las anteriores elecciones generales del mes de abril un diputado nacional por la provincia de Badajoz y de la consecución de dos (uno por la circunscripción pacense y otro por la cacereña) en los últimos comicios estatales de noviembre. Su exclusión del parlamento regional se deriva del hecho de que ni en el conjunto de la Comunidad Autónoma ni en ninguna de las dos provincias aisladamente consideradas ha alcanzado el $5 \%$ de los sufragios que es la barrera electoral establecida por normativa extremeña rectora de la materia, puesto que en Cáceres logró el 4,57\% y en Badajoz el 4,70\%, para un total a nivel global extremeño del 4,65\% de los votos.

\subsubsection{Las elecciones locales de 26 de mayo de 2019}

Es costumbre en nuestro país que las elecciones municipales coincidan con la celebración de los comicios en la mayor parte de las Comunidades Autónomas españolas. Las cifras globales de las convocatorias electorales municipales arrojan también una clara mayoría del PSOE en las provincias de Cáceres y de Badajoz.

En el conjunto del territorio cacereño, el PSOE logró más de 100.700 votos que se materializaron en 864 concejales, mientras que el PP con unos 83.300 sufragios consiguió 646 ediles. La tercera fuerza política municipal, muy alejada de las dos anteriores, fue Ciudadanos con casi 16.850 votos y 57 representantes municipales. La coalición Podemos-IUEquo ocupó la cuarta posición en número de votos con más de 10.800, que se tradujeron en 22 concejales. No obstante, el partido político Extremeños que concurrió separadamente a las municipales tuvo un mayor número de concejales (un total de 47), a pesar de lograr un número muy 
inferior de apoyos (casi 4.150). La amplia mayoría de representantes municipales del PSOE en la provincia cacereña le ha permitido presidir con mayoría absoluta su Diputación Provincial.

La victoria del PSOE en las elecciones municipales en el conjunto del territorio provincial pacense fue considerablemente más amplia, puesto que sus más de 180 mil votos se tradujeron en 873 concejales. Los casi 111.600 votos del PP y sus 498 ediles le convierten en la segunda fuerza política municipal en Badajoz. Muy alejados de PSOE y de PP han quedado Ciudadanos con algo más de 28.500 votos y 61 regidores, y Podemos-IU-Equo con casi 13.500 sufragios y 38 concejales. Su abrumadora mayoría en la representación municipal ha permitido al PSOE obtener la presidencia de la Diputación Provincial de Badajoz con mayoría absoluta.

Aunque estos son los resultados globales de una clara victoria del PSOE en las elecciones municipales del conjunto de la región, conviene, sin embargo, efectuar ciertas consideraciones sobre el gobierno municipal en algunas de las principales ciudades de la Comunidad Autónoma.

Empezando por la ciudad más poblada de la región, Badajoz, puede constatarse que la mayoría simple socialista de once concejales no le ha servido para conseguir la Alcaldía, en la medida en que existe un acuerdo para que se turnen en ella el PP y Ciudadanos (los dos primeros años para el candidato popular y los dos siguientes para el candidato naranja). Esto ha sido posible gracias a la mayoría absoluta de catorce ediles (sobre los veintisiete posibles) que supone la suma de los nueve concejales del PP, los cuatro de Ciudadanos y el concejal de Vox.

La capital cacereña tiene como alcalde, sin embargo, al líder socialista local, gracias a que el PSOE fue la lista municipal más votada con nueve concejales sobre los veinticinco posibles. A diferencia de lo sucedido en la capital pacense, los cinco ediles de Ciudadanos decidieron abstenerse, y no apoyar a los siete del PP y al único de Vox, cuya suma hubiese permitido conseguir la mayoría absoluta (y, con ello, la Alcaldía) al 
candidato popular con trece concejales de los veinticinco que constituyen el pleno del Ayuntamiento.

La Alcaldía de Mérida ha quedado en manos del candidato socialista gracias a su mayoría absoluta de catorce concejales de los veinticinco posibles.

\subsection{LA FORMACIÓN DE LA NUEVA JUNTA DE EXTREMADURA}

La Asamblea de Extremadura resultante de las elecciones autonómicas de mayo de 2019 volvió a investir el día 25 de junio de 2019 a D. Guillermo Fernández Vara como Presidente de la Junta de Extremadura, máxima magistratura autonómica esta que ya había ostentado durante los períodos 2007-2011 (VII Legislatura) y 2015-2019 (IX Legislatura). A diferencia de lo que sucedió en la anterior investidura (al comienzo de la última Legislatura en julio de 2015), en la que Fernández Vara no recibió ningún voto en contra en el Parlamento autonómico, en su reelección para este nuevo periodo parlamentario de cuatro años el nuevo Presidente ha contado con el apoyo explícito de la mayoría absoluta que conforman los treinta y cuatro diputados del grupo parlamentario socialista, que lo sustentan, pero ha recibido los votos en contra de los veinte miembros del grupo popular, mientras que los siete representantes de Ciudadanos y los cuatro de Podemos decidieron abstenerse en la votación de investidura.

Una vez efectuada esta designación parlamentaria, el Presidente dictó su Decreto 16/2019, de 1 de julio, por el que se fijó el nuevo organigrama de su gobierno, que contará con nueve Consejerías, teniendo presente que dos de los nuevos Consejeros ostentarán, asimismo, sendas Vicepresidencias de la Junta de Extremadura. Con estas líneas maestras, el nuevo edificio gubernamental, con siete mujeres y dos hombres (además del Presidente D. Guillermo Fernández Vara),queda conformado de la siguiente manera: 
1. Vicepresidencia Primera y Consejería de Hacienda y Administración Pública: D ${ }^{\mathrm{a}}$. Pilar Blanco-Morales Limones.

2. Vicepresidencia Segunda y Consejería de Sanidad y Servicios Sociales: D. José María Vergeles Blanca.

3. Consejería de Agricultura, Desarrollo Rural, Población y Territorio: $\mathrm{D}^{\mathrm{a}}$. Begoña García Bernal.

4. Consejería de Economía, Ciencia y Agenda Digital: D. Rafael España Santamaría.

5. Consejería de Educación y Empleo: Da . María Esther Gutiérrez Morán.

6. Consejería de Movilidad, Transporte y Vivienda: $\mathrm{D}^{\mathrm{a}}$. Leire Iglesias Santiago.

7. Consejería de Igualdad y Portavocía: $\mathrm{D}^{\mathrm{a}}$. Isabel Gil Rosiña.

8. Consejería de Cultura, Turismo y Deportes: $\mathrm{D}^{\mathrm{a}}$. Nuria Flores Redondo.

9. Consejería para la Transición Ecológica y Sostenibilidad: $\mathrm{D}^{\mathrm{a}}$. Olga García García.

Una comparación de esta estructura de gobierno con la existente durante la anterior Legislatura arroja como resultado las siguientes semejanzas y diferencias: en primer término, el número de nueve Consejerías de la recién nombrada Junta es superior al del gobierno autonómico inicial de la IX Legislatura que contaba tan sólo con cinco Consejerías y una Portavocía, e, incluso, más amplia que el existente justo antes de la convocatoria de elecciones en abril de 2019 (al final, por tanto, de la IX Legislatura), momento en el que ya se había elevado a seis el número de Consejerías; en segundo término, el referido gobierno autonómico originario de la anterior Legislatura carecía de Vicepresidencias, aunque es cierto que, con posterioridad -en concreto, en el momento mismo de crearse la sexta Consejería- se dotó de rango de Vicepresidenta a $\mathrm{D}^{\mathrm{a}}$. Pilar Blanco-Morales Limones, que era la titular de la Consejería de Hacienda y Administración Pública; en tercer término, eran siete los 
nombres del último gobierno de Fernández Vara al final de la pasada Legislatura, y una lectura del nuevo organigrama de la Junta de Extremadura muestra que todos esos hombres (realmente tan sólo uno) y mujeres (seis) se siguen manteniendo en la cúspide gubernamental.

El referido Decreto presidencial 16/2019 ha encontrado su desarrollo en el Decreto de la Junta de Extremadura 87/2019, de 2 de agosto, por el que se establece la estructura orgánica básica de la Administración de la Comunidad Autónoma de Extremadura -modificado por el Decreto 161/2019, de 29 de octubre-. Estas disposiciones han sido complementadas por los diversos Decretos gubernamentales (en concreto, los números 162 a 170 del año 2019) mediante los que se establece la estructura orgánica de cada una de las nueve Consejerías.

\section{LA ACTIVIDAD NORMATIVA EN EXTREMADURA}

\subsection{LA ACTIVIDAD LEGISLATIVA PARLAMENTARIA Y GUBERNAMENTAL}

\subsubsection{Un balance global de la IX Legislatura}

El año 2019 ha supuesto el final de la IX Legislatura en la Comunidad Autónoma de Extremadura dirigida por un gobierno del PSOE, presidido por D. Guillermo Fernández Vara, y que se había abierto paso en el año 2015, tras el fin de la VIII Legislatura, bajo la dirección de una Junta de Extremadura capitaneada por el líder popular D. José Antonio Monago.

En estos cuatro años, se han aprobado un total de cuarenta y cuatro leyes formales por la Asamblea Legislativa regional: tres, desde la constitución del nuevo gobierno en el verano de 2015 (hasta la convocatoria de elecciones en la primavera de ese año se habían aprobado otras dieciséis); diez, en el ejercicio de 2016; siete, en el año 2017; trece en la anualidad de 2018; y once, hasta la disolución del Parlamento autonómico en la primavera del presente año 2019 (desde el inicio de la X Legislatura se han aprobado dos leyes formales más). 
La Junta de Extremadura ha dictado, por su parte, otras cinco normas legales en este período cuatrienal: una de estas normas ha sido un decreto legislativo (en 2018), mientras que las cuatro restantes han adoptado la forma de decreto-ley. En el caso de esta última categoría normativa de legislación de urgencia: durante el año 2016 vio la luz un decreto-ley; dos en el ejercicio de 2018 y otro en febrero del presente año 2019.

4.1.2. Una consideración previa sobre la actividad legislativa durante el año 2019

Este año constituye un prototípico ejercicio de encrucijada entre dos Legislaturas. El final de la IX ha sido, como suele ser habitual en la práctica parlamentaria autonómica, bastante prolífico en la aprobación de leyes formales puesto que han visto la luz un total de once, a las que debe añadirse un decreto-ley aprobado por la Junta de Extremadura (y convenientemente convalidado por la Asamblea de Extremadura). Este número de normas legales es inferior a las dieciséis leyes aprobadas en el final de la VIII Legislatura en 2015, pero superior a las nueve normas legales de los últimos meses de la VII Legislatura en el 2011.

El comienzo de la X Legislatura ha traído consigo la aprobación de otras dos leyes formales por el Parlamento autonómico, así como tres Reformas del Reglamento de la Asamblea de Extremadura por parte del Pleno de la Cámara en sesiones celebradas el día 18 de julio de 2019 (DOE núm. 146, de 30 de julio de 2019), el 10 de octubre de 2019 (DOE núm. 201, de 17 de octubre de 2019) y el 24 de octubre de 2019 (DOE núm. 211, de 31 de octubre de 2019). En estas Reformas se han regulado, sucesivamente, la composición de la Mesa de la Cámara (compuesta por ocho miembros con voz y voto: la Presidencia, tres Vicepresidencias y cuatro Secretarías), los requisitos para el nombramiento del letrado mayor y secretario general de la Asamblea (con una primera regulación el 10 de octubre, pero inmediatamente modificada el 24 de octubre) y la 
situación de cese en la pertenencia de un diputado a un grupo parlamentario por voluntad propia o por su expulsión.

4.1.3. La legislación de urgencia adoptada por la Junta de Extremadura

Esta legislación de urgencia se ha circunscrito exclusivamente a la adopción del Decreto-ley 1/2019, de 5 de febrero, de medidas urgentes para el fomento del juego responsable en la Comunidad Autónoma de Extremadura.

Esta norma legal de urgencia ha sido dictada, según su preámbulo, en base a las competencias exclusivas regionales en el ámbito de los “(C)asinos, juegos y apuestas, incluidas las modalidades por medios telemáticos cuando la actividad se desarrolle exclusivamente en Extremadura" (art. 9.1.44 EAEx). Esta disposición legal justifica la urgencia necesaria para su adopción en "la extensión, en los últimos tiempos, de nuevas modalidades de juegos y apuestas reguladas insuficientemente, así como por la proliferación de establecimientos y el grado de participación en las mismas".

Tras esta declaración, el referido preámbulo hace la doble constatación de que, por un lado, la "ludopatía es uno de los problemas sanitarios y sociales que más se están incrementando” (en particular entre los adolescentes y los jóvenes), y de que, por otro, la intervención administrativa es esencial para la búsqueda de "un equilibrio entre la libertad de empresa y el derecho al ocio responsable, velandopara que un tiempo de ocio y de disfrute no se convierta en un juego problemático-compulsivo y, por tanto, patológico, con los consiguientes problemas personales, familiares, sanitarios y económicos para las personas implicadas”. Sobre esta base, la Junta de Extremadura ha aprobado esta norma que, en su largo artículo único, modifica diversos preceptos de la Ley 6/1998, de 18 de junio, del Juego de Extremadura, además de añadir un nuevo capítulo octavo a su texto, con la rúbrica "De la ordenación del juego responsable", y que, entre otras medidas, incorpora una serie de principios rectores 
para la ordenación del juego responsable; establece distancias mínimas para la ubicación de establecimientos de juegos y apuestas; regula el control de admisión en locales de juego y en el juego realizado por medios electrónicos, informáticos, telemáticos o interactivos; o prevé un fortalecimiento de los sistemas de inspección, vigilancia y control.

4.1.4. Las leyes formales aprobadas por la Asamblea de Extremadura

La actividad legislativa del Parlamento autonómico ha arrojado un total de trece leyes. La mayor parte de ellas (hasta un total de diez) son leyes de nuevo cuño, en el sentido de que tienen vida propia por ellas mismas, mientras que otras dos se limitan a modificar leyes autonómicas como puede vislumbrarse con una mera lectura de su rúbrica. Una última y larga norma (la Ley 8/2019, de 5 de abril, para una Administración más ágil en la Comunidad Autónoma de Extremadura) efectúa una modificación de una decena bien larga de otras normas, pero es cierto que una buena parte de su articulado no se integra en ninguna otra ley, sino que, utilizando la expresión ya referida en las líneas anteriores, tiene vida propia e independiente.

En un ensayo de mínima sistematización, las trece leyes formales autonómicas que han visto la luz esta anualidad podrían agruparse, si bien es cierto que con unas amplias dosis de voluntarismo y de discrecionalidad por nuestra parte, en torno a cinco vectores: el régimen jurídico del Gobierno y de las Administraciones Públicas en Extremadura, el económico-financiero, el social, el sistema de protección de los consumidores y, finalmente, la ordenación de los espectáculos públicos y de las actividades recreativas.

a. La legislación sobre el régimen jurídico del Gobierno y de la Administración extremeña

La categoría de leyes donde resulta prevalente la ordenación del régimen jurídico del Gobierno y de la Administración regional engloba un 
total de cuatro normas, que abordan temas tan dispares que van desde la eliminación del límite de mandatos del Presidente de la Junta, hasta la ordenación del sistema de lucha contra las emergencias, pasando por una norma que regula la autonomía municipal en Extremadura o por otra que pretende dotar de instrumentos jurídicos adecuados al aparato administrativo regional para agilizar su funcionamiento. Estas disposiciones legales son, según su orden de aprobación, las siguientes:

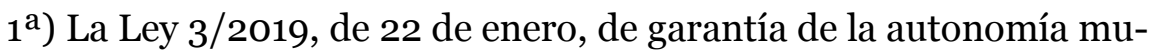
nicipal de Extremadura.

El Estatuto extremeño atribuye a la Comunidad Autónoma la competencia exclusiva sobre la "(O)rganización territorial propia de la Comunidad Autónoma y régimen local” en su art. 9.1.3. Es cierto, no obstante, que este precepto matiza inmediatamente el alcance de las potestades autonómicas al indicar que la exclusividad lo es "en los términos del Título IV de este Estatuto”. Este Título, que tiene como rúbrica “(D)e la organización territorial”, incluye en su seno dos preceptos en los que se proclama la plena autonomía política de los municipios (arts. 54.1 y 55 EAEx), encomendando a la Asamblea de Extremadura el desarrollo de estas previsiones mediante una ley que habrá de ser aprobada por mayoría cualificada. Con esta base estatutaria, el Parlamento autonómico adoptó la norma ahora reseñada, que parcialmente cumplimenta la reserva de ley de mayoría absoluta, aunque la parte restante tiene valor de ley ordinaria (disposición final primera).

El contenido material de esta Ley tiene, como ella misma reconoce, una inspiración directa en otra normativa autonómica ya existente sobre esta cuestión en Andalucía y en el País Vasco. Por lo demás, no deja de sorprender que, careciendo Extremadura de una normativa reguladora de manera integral del régimen local en la región, esta Ley pretenda tan sólo efectuar una regulación muy parcial de este ámbito y, además, con un carácter confesadamente provisional o transitorio, hasta que se construya "en el futuroel marco normativo general del gobierno local de 
Extremadura" (exposición de motivos). Así las cosas, esta Ley autonómica cuenta con tres bloques principales: uno primero, relativo a la ordenación de las competencias municipales (con una larga enumeración de competencias propias); el segundo, centrado en el establecimiento de un sistema de garantías de la autonomía local (encabezado por el Consejo de Política Local y la Comisión de Garantías de la Autonomía Local); y el tercero, referido a la financiación municipal (con la regulación de un "fondo de financiación incondicionado" para los municipios de la región).

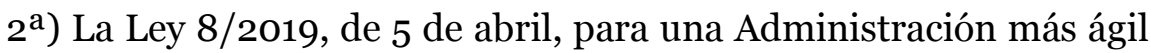
en la Comunidad Autónoma de Extremadura.

Esta nueva Ley regional cita como base jurídica para su adopción por la Asamblea de Extremadura un importante número preceptos estatutarios atributivos de competencias tanto exclusivas (las reglas núms. 1, 5, 7, 8 y 31 del apartado 1 del art. 9 EAEx) como compartidas (las reglas 1 y 2 del apartado 1 del art. 10 EAEx) a nuestra región, sin olvidar la referencia al art. 39.2 del propio texto estatutario, que al regular las “(M)edidas de buena administración" dispone literalmente que: "La Comunidad Autónoma regulará los procedimientos administrativos propios y adaptará los procedimientos generales para dar celeridad y transparencia a la tramitación administrativa, para extender las relaciones interadministrativas y con los ciudadanos por medios telemáticos y para la simplificación de trámites".

Partiendo de esta base jurídica, el objeto de la Ley reseñada es doble: por un lado, "el establecimiento de medidas de impulso para facilitar la actividad empresarial en la Comunidad Autónoma de Extremadura”; y, por otro, "la adopción de medidas de simplificación y mejora de la Administración autonómica" (art. 1.1). Y todo ello, con la finalidad de "lograr un funcionamiento más eficaz y eficiente de la Administración autonómica de Extremadura, adaptado a las necesidades de los ciudadanos" (art. 1.2). A tal efecto, la norma legal reseñada contempla una importante cantidad de medidas que, en ocasiones, mantienen una vida autónoma 
dentro de ella, al no modificar normas ya existentes (esto ocurre, por ejemplo, con la regulación de las exenciones fiscales para sujetos que inicien o amplíen sus actividades profesionales en el territorio extremeño; la mejora de la regulación en materia de montes; o las medidas para la implantación de la Administración digital), pero que, en buena parte de los casos, están llamadas a incluirse en disposiciones generales ya existentes, que son modificadas, a veces de manera ciertamente intensa, por esta nueva Ley. Esto último sucede nada menos que con quince leyes autonómicas, siendo especialmente considerable la reforma operada en las cuatro siguientes: la Ley 16/2015, de 23 de abril, de Protección Ambiental; la Ley 2/2008, de 16 de junio, de Patrimonio; la Ley 5/2007, de 19 de abril, General de Hacienda Pública; y la Ley 6/2011, de 23 de marzo, de Subvenciones.


emergencias de la Comunidad Autónoma de Extremadura.

Esta Ley, que está dictada en virtud de las competencias exclusivas de la Comunidad Autónoma en materia de protección civil y emergencias (art. 9.1.42 EAEx), constituye una absoluta novedad dentro del ordenamiento jurídico regional, pues es la primera vez que se aborda en Extremadura la regulación general de la previsión y de la respuesta ante las situaciones de emergencia. El contenido de esta disposición regional se desarrolla, según su exposición de motivos, dentro del marco ofrecido por la legislación básica estatal establecida en la Ley 17/2015, de 9 de julio, del Sistema Nacional de Protección Civil, con la finalidad de poner en pie para el ámbito territorial extremeño un sistema global de protección civil y emergencias, denominado Sistema Regional de Protección Civil y de Gestión de Emergencias de la Comunidad Autónoma de Extremadura, que "responda a la obligación de las Administraciones de proteger la vida y la integridad de las personas, el patrimonio medioambiental y la protección de sus bienes". En este orden de ideas, son numerosas las cuestiones reguladas por esta nueva norma legal, pudiendo destacarse, entre ellas, las siguientes: en primer lugar, los derechos y los deberes 
ciudadanos en este ámbito; en segundo lugar, el importante papel del voluntariado y de las entidades colaboradoras; en tercer lugar, la estructura, los instrumentos y el funcionamiento del Sistema Regional de Protección Civil; en cuarto lugar, las competencias de la Junta de Extremadura y el régimen de colaboración, de cooperación y de coordinación con el resto de Administraciones públicas; en quinto lugar, la participación ciudadana en este ámbito material (que se canaliza, esencialmente, a través de la Mesa Social de Protección Civil y Emergencias de la Comunidad Autónoma de Extremadura); y en sexto lugar, el régimen sancionador.

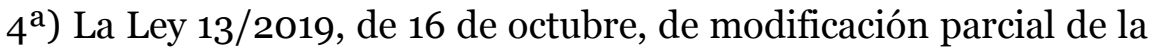
Ley 1/2014, de 18 de febrero, de regulación del estatuto de los cargos públicos del Gobierno y la Administración de la Comunidad Autónoma de Extremadura.

A pesar de que esta nueva norma legal autonómica es de artículo único, ha encontrado una enorme resonancia dentro del ámbito políticoinstitucional extremeño por la cuestión que aborda. En efecto, la Asamblea de Extremadura aprobó durante el año 2014 la limitación de mandatos para el Presidente de la Junta de Extremadura. Pues bien, esta limitación ha sido suprimida mediante la derogación del art. 8.3 de la referida Ley autonómica aprobada en la parte final de la VIII Legislatura autonómica, bajo la Presidencia de la Junta de Extremadura por el máximo dirigente regional del Partido Popular, D. José Antonio Monago.

La justificación esencial de la medida contenida en la Ley ahora reseñada se efectúa mediante la apelación a distintos informes de organizaciones internacionales (en concreto, del Consejo de Europa, a través de la Comisión de Venecia) o de órganos estatutarios autonómicos (específicamente, del Consejo Económico y Social de Extremadura y del desaparecido Consejo Consultivo de Extremadura). A partir de estas opiniones jurídicas, y de la constatación de que el Estatuto de Autonomía extremeño no habilita "al legislador autonómico a establecer tales limitaciones a diferencia de lo que ocurre en algún otro Estatuto de 
Autonomía”, la exposición de motivos de la Ley concluye que resulta necesario eliminar la limitación de mandatos para concurrir a la Presidencia de la Junta de Extremadura "a fin de garantizar el principio de igualdad en la aplicación de la Constitución, las normas electorales y en el acceso a los cargos electivos de representación política”.

\section{b. La ordenación de la actividad económica-financiera}

El objetivo de la ordenación de la actividad económico-financiera regional está presente en las siguientes dos leyes:

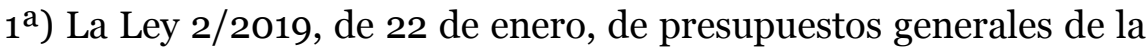
Comunidad Autónoma de Extremadura para el año 2019.

Durante las cuatro anualidades de la IX Legislatura, la aprobación de las cuentas autonómicas se ha producido una vez iniciado el período presupuestario al que se han aplicado. El desvío temporal se ha reducido, en este caso, a algo más de tres semanas, pues esta norma fue publicada en el Diario Oficial de Extremadura del 24 de enero de 2019.

La Ley presupuestaria incide en su doble vertiente de apoyo social y de desarrollo económico. Con respecto a la primera dimensión, señala la exposición de motivos que, si durante los ejercicios anteriores los Presupuestos persiguieron "la recuperación de los servicios fundamentales, la consolidación de las políticas públicas y el fortalecimiento de la cohesión social", las nuevas previsiones contenidas en la Ley pretenden acentuar “el sesgo social”, pues “dedican 6,4 de cada 10 euros a estas políticas”. En este orden de ideas, si los Presupuestos autonómicos de 2019 casi alcanzan la cifra de cinco mil setecientos noventa y ocho millones, de ellos más de mil seiscientos noventa estarían asignados a sanidad y más de mil setenta lo estarían a educación. En relación con la segunda perspectiva, el preámbulo del texto normativo indica que las previsiones contemplan "un alza del 4,3\% en las actuaciones de carácter económico", hasta alcanzar más de mil cuatrocientos veinte millones de euros la cantidad orientada a "promover el desarrollo de la estructura productiva de la región". 
Un año más se contienen previsiones en la norma presupuestaria con el objeto de incorporar a los presupuestos regionales las eventuales asignaciones que consignen los Presupuestos Generales del Estado a favor de la Comunidad Autónoma de Extremadura en los dos conceptos recogidos por las disposiciones adicionales primera y segunda del Estatuto de Autonomía (es decir, como pago, respectivamente, de la llamada "deuda histórica" y de las inversiones complementarias en infraestructuras por el uno por ciento del PIB regional).

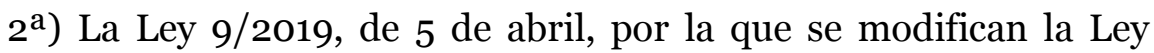
14/2010, de 9 de diciembre, de caza de Extremadura, y la Ley 18/2001, de 14 de diciembre, sobre tasas y precios públicos de la Comunidad Autónoma de Extremadura.

Esta norma legal tiene como objetivo la modificación de diversas leyes autonómicas. En su rúbrica se refiere a dos: la Ley de caza de 2010 y la Ley sobre tasas y precios públicos de 2001. No obstante, la lectura de su texto permite constatar que esta norma modifica dos leyes autonómicas más: la Ley 11/2010, de 16 de noviembre, de Pesca y Acuicultura de Extremadura, y la Ley 5/2002, de 23 de mayo, de Protección de los Animales en la Comunidad Autónoma de Extremadura. Es cierto que las modificaciones son realmente muy puntuales, destacando, quizá, las previsiones referidas al establecimiento de una licencia regional única para todas las modalidades tanto del ámbito de la caza (art. 1.9) como del de la pesca (art. 3). Una última consideración sobre esta norma legal: en la medida en que esta Ley no procede a una regulación integral de ningún sector de actividad, sino a la modificación de otras normas existentes, no se encuentra apelación alguna a los títulos competenciales autonómicos ni en su exposición de motivos ni en su articulado.

c. Las leyes de naturaleza eminentemente social

Cuentan con una naturaleza eminentemente social hasta un total de cinco leyes: 


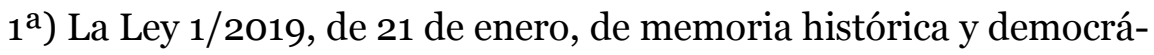
tica de Extremadura.

Aunque esta primera norma legal autonómica del presente año no cita ningún título competencial estatutario, sí apela en su exposición de motivos a los dos principios rectores iniciales del art. 7 EAEx, luego reiterados -aunque sin referencia numérica explícita- en el art. 1.2 del nuevo texto legislativo. La lectura del largo preámbulo aludido parece conducir a la idea de que el Legislador extremeño justifica su actividad normativa en las importantes carencias observadas en la norma que regula esta cuestión en el ámbito estatal: la Ley de las Cortes Generales 52/2007, de 26 de diciembre, por la que se reconocen y amplían derechos y se establecen medidas en favor de quienes padecieron persecución o violencia durante la guerra civil y la dictadura. Y es que, a pesar de los indudables avances que se habrían producido tras la aprobación de esta disposición general, serían todavía "numerosas las labores pendientes en orden a la recuperación efectiva de la Memoria Histórica, tanto en el conjunto de la geografía nacional como, de manera particular, en la Comunidad Autónoma extremeña”.

En este contexto, esta nueva Ley autonómica tiene como objetivos explícitos la recuperación de la memoria histórica en relación con las personas extremeñas que padecieron persecución o violencia durante la Guerra Civil y la Dictadura, regulando en su articulado las políticas públicas necesarias para tal fin, además de facilitar el conocimiento de las diversas formas de la represión franquista en la región y de establecer el derecho de los descendientes de estas víctimas al desarrollo de "actividades de indagación, localización e identificación de las personas desaparecidas” y, cuando así lo soliciten, "a exhumar a sus familiares y darles una sepultura digna” (art. 1). Creo que merece una consideración especial el hecho de que la Ley incluye entre las víctimas de la represión a los bebés sustraídos y dados en adopción, así como a sus familiares más directos (art. 5, letra l). 


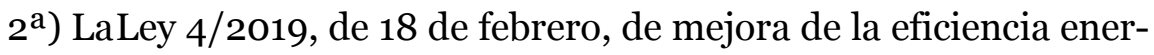
gética y las condiciones térmicas y ambientales de los centros educativos extremeños.

Los desajustes climáticos que en los últimos años ha sufrido la región, elevando considerablemente las temperaturas durante el desarrollo del calendario escolar e incidiendo, por tanto, sobre las condiciones en las que se desarrolla la enseñanza en los centros educativos de nuestra tierra (no siempre adaptados a las necesidades del tiempo presente), llevaron a la Asamblea de Extremadura a la aprobación de esta norma legal, que tiene como objetivo, además de aportar su contribución a la reducción de la huella de carbono a lo largo de la vida útil de las edificaciones, la creación de las condiciones de comodidad higrotérmica (esto es, la ausencia de malestar térmico) y de calidad y renovación del aire en dichas instalaciones, con la finalidad última "de ofrecer a la ciudadanía extremeña un servicio educativo de calidad, respetuoso con la sostenibilidad ambiental y con la salud laboral" (art. 1.1). En este marco, la nueva Ley prevé diversos instrumentos de intervención en materia energética (auditorías energéticas, planes de mejora de la eficiencia energética, etc.), así como la activación de los medios financieros para su implementación a través, sobre todo, de planes plurianuales de inversiones en infraestructuras educativas.

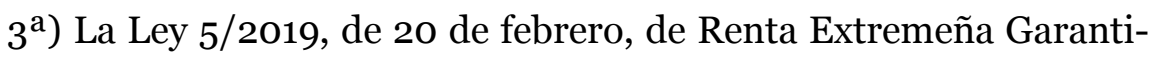
zada.

Esta norma legal cita como base las competencias autonómicas exclusivas en materia de acción social (art. 9.1.27 EAEx), así como el principio rector de la actividad de los poderes públicos extremeños que propugna la necesidad de que éstos velen "por la especial protección de aquellos sectores de población con especiales necesidades de cualquier tipo" (art. 7.14 EAEx). El punto de partida de la Ley consiste en la constatación del aumento de la pobreza propiciado por la crisis económica, que hace que sea muy significativo en nuestra región tanto "el número y 
porcentaje como la heterogeneidad de las personas que no pueden cubrir sus necesidades básicas" (exposición de motivos).

El antecedente de la disposición legal ahora reseñada ha sido la regulación de la renta básica extremeña de inserción, que queda sustituida por la nueva renta básica garantizada. Esta prestación tiene un contenido económico y es de naturaleza periódica y finalista, resultando, además, complementaria con respecto a la percepción de otros ingresos públicos (art. 3). Así definida esta "prestación básica”, la Ley tiene como objetivo primario el establecimiento de un derecho subjetivo a la percepción de la misma en el ámbito territorial extremeño con el fin de "asegurar los mínimos de una vida digna a las personas y unidades familiares" y de "promover la integración laboral y social de aquellos que se encuentren en situación o riesgo de exclusión social" (art. 1, párrafo primero). Junto a la ordenación general de este primer derecho subjetivo, la Ley regula uno segundo: "el derecho a la inclusión social de toda la ciudadanía extremeña” (art. 1, párrafo segundo). En este último orden de ideas, los extremos tendrán, asimismo, el derecho "a recibir apoyos y acompañamiento personalizado orientado a la inclusión plena y efectiva en la sociedad, en todas sus dimensiones (económica, laboral, habitacional, social y educativa) que promueva un nivel de vida y bienestar adecuados y una ciudadanía de pleno derecho" (art. 29.1). Este derecho se materializará a través de medidas personalizadas articuladas en torno a los Programas de Acompañamiento para la Inclusión, que se individualizan para cada persona interesada a través de un Acuerdo de Acompañamiento Social para la Inclusión.

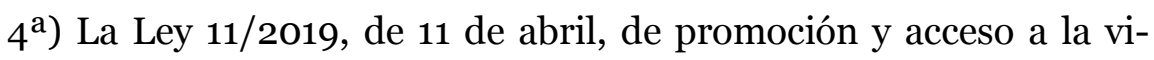
vienda de Extremadura.

Esta norma legal, que pretende desarrollar el derecho a disfrutar de una vivienda digna y adecuada -contemplado como principio rector de la política social y económica por el art. $47 \mathrm{CE}-$, ha sido dictada en base a las competencias exclusivas autonómicas en materia de urbanismo, 
vivienda y normas de calidad e innovación tecnológica en la edificación y de conservación del patrimonio urbano tradicional (art. 9.1.31 EAEx), sin perjuicio de que su exposición de motivos aluda a otros títulos competenciales como el fomento del desarrollo económico y social de la Comunidad Autónoma (art. 9.1.7 EAEx), la acción social (art. 9.1.27 EAEx) o la protección medioambiental (art. 9.1.33 EAEx).

La intervención de la Comunidad Autónoma de Extremadura en el ámbito de la vivienda tiene una historia de dos décadas bien largas y ha dado lugar a la aprobación de numerosas normas, entre las que destacan, sin duda, la Ley 3/2001, de 26 de abril, de la calidad, promoción y acceso a la vivienda de Extremadura, o la Ley 2/2017, de 17 de febrero, de emergencia social de la vivienda de Extremadura. Precisamente esta última norma preveía la elaboración de una "nueva regulación en materia de vivienda" (disposición transitoria tercera). Esta previsión normativa se ha hecho realidad con la aprobación de la Ley ahora reseñada, que es la más larga del presente año con ciento veintinueve artículos y un buen número de disposiciones adicionales, transitorias y finales (además de una disposición derogatoria única).

Su objeto consiste, por un lado, en la garantía en el territorio regional extremeño del "derecho constitucional y estatutario a una vivienda digna, de calidad, accesible y adecuada a su situación personal, familiar, económica, social y capacidad funcional, asegurando a la ciudadanía una debida calidad de vida"; estableciendo, por otro lado, "los principios que han de inspirar las condiciones técnicas de calidad e innovación tecnológica en la edificación y medidas de fomento e impulso de la calidad arquitectónica en la Comunidad Autónoma de Extremadura" (art. 1.1). Con este doble objetivo, la Ley comentada regula, entre otras cuestiones, las siguientes: en primer lugar, las finalidades, los principios rectores y los valores que pretende proteger; en segundo lugar, el ámbito competencial de la Administración pública extremeña en materia de vivienda, así como sus prerrogativas; en tercer lugar, las técnicas de intervención administrativa; en cuarto lugar, los mecanismos de protección de consumidores 
y usuarios en el acceso a este tipo de bienes; en quinto lugar, el fomento público de la vivienda y de la calidad de la edificación; en sexto lugar, el régimen jurídico aplicable para la enajenación de viviendas protegidas de promoción pública; en séptimo lugar, el proceso edificatorio; en octavo lugar, el régimen sancionador; en noveno lugar, los órganos de participación en el ámbito de la vivienda; o, en fin, la ordenación jurídica de las situaciones de emergencia social en este ámbito.

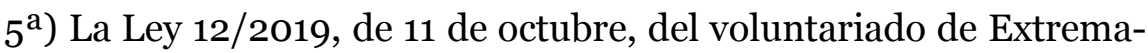
dura.

Esta norma legal cita en su preámbulo una buena cantidad de preceptos estatutarios que servirían de soporte a la Comunidad Autónoma de Extremadura para la aprobación de la misma y, entre ellos, uno específico en materia de voluntariado, el art. 9.1.45, cuyo inciso final establece la competencia exclusiva regional para el "(F)omento del voluntariado".

Esta nueva Ley pretende la sustitución del marco normativo rector del voluntariado en Extremadura, que cuenta ya con una larga tradición, para adaptarlo a las vigentes necesidades sociales y al marco regulador de esta materia a nivel estatal contenido en la Ley de las Cortes Generales 45/2015, de 14 de octubre, de Voluntariado. Explica el preámbulo de la Ley autonómica ahora reseñada que su texto ha sido fruto del "diálogo social” encauzado a través de "un grupo de trabajo político y civil conformado por la Junta de Extremadura, la Plataforma del Voluntariado de Extremadura, la Plataforma del Tercer Sector de Extremadura y todos los grupos políticos del arco parlamentario con representación en la Asamblea de Extremadura”.

En cuanto a su contenido, la Ley persigue distintos objetivos que podrían sintetizarse en los siguientes: en primer término, la ordenación, la protección y el fomento del voluntariado en el ámbito territorial extremeño; en segundo término, la promoción de la participación ciudadana en actividades de voluntariado llevadas a cabo a través de entidades de 
voluntariado, tanto dentro como fuera de nuestra región; en tercer término, el apoyo a la generación de redes comunitarias de voluntariado; en cuarto término, la ordenación de las relaciones entre las organizaciones ciudadanas en las que se integran las personas voluntarias y las distintas Administraciones públicas (con la inclusión por primera vez en una norma legal del Consejo Extremeño del Voluntariado como "órgano de participación, relación y consulta de la Administración autonómica en materia de voluntariado"); y en quinto término, el reconocimiento de los derechos de los voluntarios, de las entidades de voluntariado y de las personas destinatarias de la acción voluntaria.

\section{d. La protección de los consumidores y usuarios}

La importante y compleja materia de la protección de los derechos de los consumidores y usuarios es la protagonista de la Ley 6/2019, de 20 de febrero, del Estatuto de las personas consumidoras de Extremadura.

Esta norma legal ha sido dictada en desarrollo del principio rector de la política social y económica previsto en el art. 51 de nuestro texto constitucional, y sobre la base de la competencia exclusiva autonómica en materia de consumo en general, y para la "regulación de las medidas de prevención, protección y defensa de los consumidores y usuarios, de sus derechos y de los órganos y procedimientos de mediación”, así como para la "lucha contra el fraude" en particular (art. 9.1.18 EAEx). Esta nueva disposición legal sustituye a la vieja Ley 6/2001, de 24 de mayo, del Estatuto de los Consumidores de Extremadura, modificada en múltiples ocasiones desde su aprobación originaria por la Asamblea de Extremadura.

Su finalidad confesada en la exposición de motivos consiste en el reforzamiento en el ámbito territorial extremeño de "la defensa de los derechos de las personas consumidoras, adaptándose a los nuevos escenarios en los que se producen las relaciones de consumo" (con una extraordinaria extensión del comercio electrónico en un mercado cada vez más 
globalizado), teniendo en cuenta para ello la nueva normativa europea y estatal, así como la jurisprudencia más reciente de nuestro Tribunal Constitucional y de la Sala Tercera del Tribunal Supremo. En este contexto, la nueva Ley regula, en primer término, y con gran amplitud, los derechos de las personas consumidoras (con especial atención a sus derechos básicos, a la protección de su salud y de su seguridad, así como de sus intereses económicos y sociales, a la regulación de las indemnizaciones por los eventuales daños y perjuicios, a su derecho a la información y a sus derechos a la educación, a la formación y a la divulgación en materia de consumo); en segundo término, los mecanismos de representación, consulta y participación de los consumidores y usuarios; en tercer término, los mecanismos de inspección y de control de los bienes y servicios; en cuarto término, la potestad sancionadora; y en quinto término, y de manera tan particular como sensible en nuestra Comunidad Autónoma, el funcionamiento de las instalaciones de venta al público al por menor de gasolinas y gasóleos de automoción.

e. El régimen jurídico de los espectáculos públicos y de las actividades recreativas

El elenco de las problemáticas abordadas por el Legislador extremeño durante el presente año se cierra con la ordenación general de una materia que tiene una triple cara social, económica y administrativa, como es la relativa a los espectáculos públicos y las actividades recreativas. Esta cuestión se regula, en concreto, mediante la Ley 7/2019, de 5 de abril, de espectáculos públicos y actividades recreativas de la Comunidad Autónoma de Extremadura.

Esta norma legal ha sido dictada en base a las competencias exclusivas autonómicas en materia de espectáculos públicos y actividades recreativas (art. 9.1.43 EAEx). Debe tenerse en cuenta que, hasta la aprobación de la presente Ley, esta materia carecía de una regulación regional de alcance general, por lo que se aplicaba supletoriamente la normativa estatal. Tan sólo durante el año 2016 se dictó una Ley regional (la 
Ley 4/2016, de 6 de mayo) que pretendía salvar la laguna que en materia sancionatoria se había producido con la derogación de la Ley Orgánica 1/1992, de 21 de febrero, sobre Protección de la Seguridad Ciudadana, por obra de la Ley Orgánica 4/2015, de 30 de marzo, de Protección de la Seguridad Ciudadana.

La presente norma legal ahora reseñada responde, por lo tanto, y tal y como confiesa su exposición de motivos, a "la absoluta necesidad de completar el ejercicio de las competencias asumidas por la Comunidad Autónoma de Extremadura mediante una norma propia con rango de ley que dé adecuada satisfacción a los problemas que se plantean en la actualidad y que asiente unos principios que permitan hacer frente a los que genere la evolución de la sociedad”. Apreciado el vacío normativo y la necesidad de paliarlo, la Ley tiene como punto de partida la pretensión de conciliar la trascendencia social y económica que representa el ocio con el imprescindible respeto de "otros bienes jurídicos igual de importantes”, citando su exposición de motivos al respecto: el derecho al descanso, los derechos de los consumidores y usuarios, la seguridad y la salubridad pública, el respeto al medio ambiente, la preservación del patrimonio histórico-artístico, la plena asunción de la perspectiva de género, etc.

En este contexto, la nueva Ley tiene como objetivo la ordenación del régimen jurídico general de los espectáculos públicos y de las actividades recreativas que se desarrollen en establecimientos públicos, instalaciones o espacios abiertos en el ámbito territorial extremeño, con la finalidad de proteger los bienes jurídicos de interés general reseñados con anterioridad. A este respecto, la norma legal presta especial atención a, en primer término, la organización administrativa en la materia, que, según declara su preámbulo, está impregnada de una clara vocación descentralizadora hacia los ayuntamientos; en segundo término, la regulación de los distintos instrumentos de intervención administrativa; en tercer término, el régimen normativo aplicable a la organización y al desarrollo de este tipo de actividades; en cuarto término, el sistema de vigilancia e 
inspección de las mismas; y, en quinto y último término, su régimen sancionador.

\subsection{LA ACTIVIDAD REGLAMENTARIA Y ADMINISTRATIVA DE LA JUNTA DE}

\section{EXTREMADURA Y DE SU PRESIDENTE}

\subsubsection{Los Decretos del Presidente de la Junta de Extremadura}

Los años de finalización y de comienzo de Legislaturas suelen caracterizarse por un aumento de la actividad formalizada del Presidente de la Junta de Extremadura a través de Decretos, que sirven para la aprobación tanto de decisiones de naturaleza singular como de verdaderas disposiciones generales con valor reglamentario. Este año 2019 no ha sido precisamente una excepción, dado que el titular de la máxima magistratura autonómica ha dictado treinta y seis Decretos del Presidente (siete antes de las elecciones regionales y los veintinueve restantes con posterioridad). Este elevado número es, sin duda, similar a los treinta y ocho firmados en 2015 entre los Presidentes Monago, primero, y Fernández Vara, después.

La absoluta mayoría de los decretos presidenciales durante el presente ejercicio ha estado dirigida al cese y al nombramiento de Consejeros de la Junta de Extremadura, así como a la delegación en ellos por parte del Presidente autonómico de la firma de los convenios de colaboración con el Estado suscritos por nuestra región en el ámbito de sus correspondientes competencias. Fuera de estas disposiciones, y de las características convocatorias de subvenciones en los sectores de actividad sobre los que el Presidente ejerce directamente sus potestades, los tres Decretos del Presidente más significativos han sido el relativo a la convocatoria de elecciones a la Asamblea de Extremadura (Decreto del Presidente $1 / 2019$, de 1 de abril), el referido a la convocatoria de la sesión constitutiva del Parlamento autonómico (Decreto del Presidente 8/2019, de 3 de junio) y el consagrado a la modificación de la denominación, del 
número y de las competencias de las Consejerías que conforman la Administración de la Comunidad Autónoma de Extremadura (Decreto del Presidente 16/2019, de 1 de julio).

\subsubsection{Los Decretos de la Junta de Extremadura}

El número "oficial” de decretos gubernamentales durante este año de comienzo de la X Legislatura es de 204, que es una cifra bastante inferior a las de los inicios de la IX y de la VIII Legislatura, puesto que en 2015 se aprobaron 323 y en 2011 un total de 305. Es cierto que, exceptuando precisamente el año 2015, el número de disposiciones gubernamentales de este final de ciclo no es muy distinto, cuanto menos sobre el papel, al de los años 2016, 2017 y 2018 en los que se dictaron 215, 220 y 212 respectivamente. De todas las disposiciones gubernamentales con la forma jurídica de decreto de este ejercicio de 2019 únicamente 65 fueron emanadas antes de la conformación del nuevo gobierno extremeño en los albores del mes de julio.

Entrecomillábamos premeditadamente en el párrafo anterior el adjetivo "oficial” que servía para calificar al sustantivo "número" (de decretos de la Junta de Extremadura), y esta circunstancia requiere los siguientes comentarios: $1^{0}$ ) En primer término, esta cifra “oficial” proviene de que ya comenzado el año 2020 se han publicado los Decretos 203/2019, de 27 de diciembre (DOE núm. 3, de 7 de enero de 2020) y 204/2019, de 27 de diciembre (en un diario oficial anterior: DOE núm. 2, de 3 de enero de 2020); $2^{\circ}$ ) En segundo término, en el DOE núm. 247, de 26 de diciembre de 2019, se publicaron cuatro decretos fechados en octubre (en concreto, los Decretos 187/2019, 188/2019 y 189/2019, de 15 de octubre -todos ellos- y el Decreto 200/2019, de 22 de octubre), a pesar de que el DOE ha publicado numerosos decretos con un número anterior al 187, pero con una fecha posterior a octubre (por ejemplo, el Decreto 185/2019, de 17 de diciembre -DOE núm. 245, de 23 de diciembre-, o el Decreto 186/2019, de 17 de diciembre-DOE núm. 249, de 30 de diciembre de 2019-); y $3^{\circ}$ ) En tercer término, nótese que en el 
referido DOE núm. 247, de 26 de diciembre de 2019, se publican el Decreto 189/2019 y, acto seguido, el Decreto 200/2019. Estos datos nos llevan a pensar que ha podido producirse un error en la numeración de los decretos gubernamentales, no habiéndose dictado (y, por tanto, no existiendo realmente) esta anualidad los Decretos núms. 190 a 199. Debe destacarse, asimismo, que no parece compatibilizarse mucho con una buena técnica normativa que decretos publicados en el DOE con un ordinal más avanzado tengan una fecha anterior a otros con una numeración inferior, pero con fecha posterior (compárese, por ejemplo, el Decreto 189/2019, de 15 de octubre, con el Decreto 186/2019, de 17 de diciembre). De ser ciertas estas consideraciones, la conclusión final resultante es que el número "oficial” de decretos (204) no coincidiría con el número "real”. Este último número sería de 194 decretos; una cifra inferior en diez unidades a la oficial.

En todo caso, el decreto gubernamental ha sido la forma de aprobación de distintas normas reglamentarias, pero, sobre todo, de una gran cantidad de actos singulares. Como todas las anualidades de nacimiento de una nueva Legislatura, en 2019 han destacado, sin ningún género de dudas, los referidos a los ceses y nombramientos de los altos cargos que sirven para configurar el Gobierno y la Administración autonómica, a los que debe añadirse, a comienzos de año el Decreto 2/2019, de 8 de enero, para el nombramiento de don Antonio Hidalgo García, como nuevo Rector de la Universidad de Extremadura, tras las elecciones celebradas en esta institución académica a finales de 2018. El número de este tipo de decretos casi ha alcanzado las nueve decenas, que constituye una cantidad muy superior a la de cualquier otra temática abordada durante el presente ejercicio por la Junta de Extremadura. Este ámbito material ha superado con creces durante esta anualidad, incluso, la que ejercicio tras ejercicio suele ser la materia estrella de la actividad gubernamental regional (las subvenciones y otros tipos de ayudas), que ha ocupado, ciertamente, el segundo lugar desde un punto de vista cuantitativo, pero a una gran distancia de la referida cuestión relativa a la designación y al 
cese de altos cargos, pues su número no ha llegado ni siquiera a la treintena de decretos.

Con independencia de las temáticas referidas a los ceses y nombramientos de altos cargos y a las subvenciones, el resto de las disposiciones gubernamentales se han centrado, como es habitual año tras año en nuestra región, en materias como, entre otras, las siguientes: la aprobación del programa estadístico anual; la fijación del calendario de días festivos e inhábiles en el territorio regional; la declaración de la urgente ocupación de bienes y derechos en el marco de procedimientos de expropiación forzosa; las declaraciones de monumentos naturales y de bienes de interés cultural; la salud humana y animal; la dependencia; la ordenación de la vivienda; la educación universitaria y no universitaria; la ordenación de la estructura orgánica básica de las diversas Consejerías de la Junta de Extremadura y de la Administración autonómica, así como la regulación de diversos aspectos relativos al personal a su servicio; la actualización del planeamiento en materia de protección civil; la policía local; la comunicación audiovisual; el turismo; la agricultura; la aprobación de reglamentos de denominación de origen protegida de diversos productos; la regulación de diversas actuaciones forestales; la modificación de la ordenación de proyectos de interés regional; o la concesión de la medalla de Extremadura.

V5 LA CONFLICTIVIDAD ENTRE LA COMUNIDAD AUTÓNOMA DE EXTREMADURA Y LA ADMINISTRACIÓN GENERAL DEL ESTADO

5.1. LAS CONTROVERSIAS FORMULADAS EN EL SENO DE LA COMISIÓN BILATERAL DE COOPERACIÓN ADMINISTRACIÓN GENERAL DEL ESTADO-COMUNIDAD AUTÓNOMA DE EXTREMADURA

Esta anualidad se ha caracterizado por la existencia de un muy notable número de controversias entre la Comunidad Autónoma de Extremadura y la Administración General del Estado, provocando en hasta ocho 
ocasiones el inicio de negociaciones para solventar discrepancias sobre la constitucionalidad de diversas normas autonómicas con rango de ley en el seno de la Comisión Bilateral de Cooperación.

a) De estos ocho conflictos, y en primer lugar, cuatro han quedado totalmente solventados a través de sendos acuerdos adoptados por la propia Comisión Bilateral a lo largo de este mismo año. En efecto, han quedado solucionadas de este modo las discrepancias formuladas por la Administración General del Estado en relación con diversos preceptos de dos normas legales autonómicas de 2018 y de otras dos de 2019:

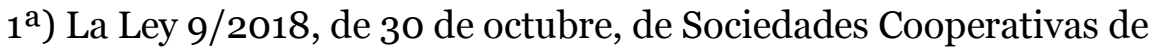
Extremadura. Las negociaciones en el seno de la Comisión Bilateral tuvieron su origen en un Acuerdo de 8 de enero de 2019, quedando concluidas de manera satisfactoria para ambas partes mediante Acuerdo de 15 de mayo de 2019.


fica la Ley 2/2002, de 25 de abril, de protección de la calidad del suministro eléctrico en Extremadura. Las negociaciones sobre la constitucionalidad del apartado primero del artículo único de esta norma legal de urgencia se iniciaron por Acuerdo de 23 de enero de 2019, resolviéndose las discrepancias por Acuerdo de 8 de julio de 2019.

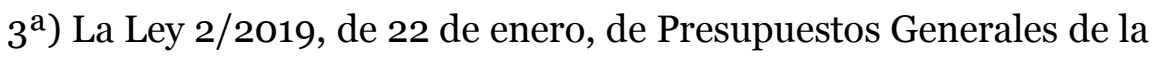
Comunidad Autónoma de Extremadura para el año 2019. El debate jurídico sobre la constitucionalidad de dos preceptos de esta Ley autonómica se inició a través de un Acuerdo de 12 de marzo de 2019 y se ultimó, a satisfacción de ambas partes, por Acuerdo de 26 de julio de 2019.

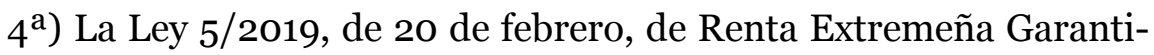
zada. Las discrepancias expresadas por la Administración General del Estado sobre el ajuste constitucional de un precepto de esta Ley autonómica provocaron la apertura de negociaciones en el seno Comisión 
Bilateral por Acuerdo de 7 de mayo de 2019, llegándose a una solución consensuada mediante Acuerdo de 3 de octubre de 2019.

b) En segundo lugar, aunque este órgano mixto ha iniciado, a través de la firma de los correspondientes acuerdos, las negociaciones para la resolución de las desavenencias suscitadas por la Administración General del Estado, sigue todavía pendiente en el momento de redactar este trabajo un pronunciamiento definitivo sobre la constitucionalidad de diversos preceptos de las siguientes normas legales autonómicas:

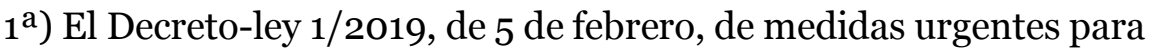
el fomento del juego responsable en la Comunidad Autónoma de Extremadura. El comienzo de las negociaciones sobre los dos preceptos controvertidos de esta norma legal de urgencia tuvo lugar mediante Acuerdo de 24 de abril de 2019.

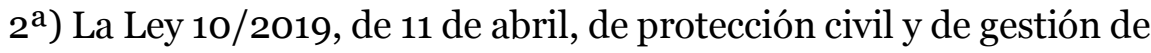
emergencias de la Comunidad Autónoma de Extremadura. Mediante Acuerdo de 18 de junio de 2019, la Comisión Bilateral decidió iniciar las negociaciones para resolver las controversias constitucionales en torno a tres preceptos de esta Ley regional.

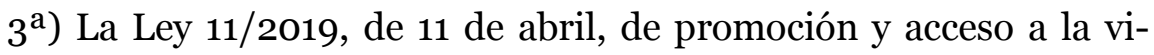
vienda de Extremadura. Las negociaciones para la resolución de las discrepancias constitucionales sobre más de una decena de disposiciones de esta Ley autonómica se iniciaron mediante Acuerdo de 10 de julio de 2019 .

c) En tercer lugar, ya iniciado el presente año, en concreto en el DOE núm. 15, de 23 de enero de 2019, se publicó el Acuerdo de 20 de noviembre de 2018, de la Comisión Bilateral de Cooperación, mediante el que se puso fin a la controversia constitucional que enfrentaba a la Administración General del Estado con la Comunidad Autónoma de Extremadura en relación con algunos preceptos de la Ley autonómica 4/2018, de 21 de 
febrero, por la que se modifica la Ley 6/2001, de 24 de mayo, del Estatuto de los Consumidores de Extremadura.

d) En cuarto y último lugar, por Acuerdo de 17 de abril de 2019 se iniciaron negociaciones en el seno de la Comisión Bilateral de Cooperación para la resolución de las controversias sobre diversos preceptos de la Ley 6/2019, de 20 de febrero, del Estatuto de las personas consumidoras de Extremadura. Estas negociaciones no parece que hayan alcanzado el resultado positivo esperado en la medida en que el DOE núm. 249, de 30 de diciembre de 2019, ha publicado el edicto del Tribunal Constitucional de 10 de diciembre de 2019 en el que se da cuenta de que el Pleno de este órgano ha acordado la admisión a trámite del recurso de inconstitucionalidad núm. 6835-2019, promovido por el Presidente del Gobierno de la Nación, a través de la Abogacía del Estado, contra cuatro preceptos de la referida Ley autonómica destinada a la protección de los consumidores en nuestra región.

5.2. LA JURISPRUDENCIA CONSTITUCIONAL CON ESPECÍFICA RELEVANCIA PARA LA COMUNIDAD AUTÓNOMA DE EXTREMADURA

\subsubsection{Planteamiento general}

Durante el presente ejercicio, el Tribunal Constitucional ha dictado tres Sentencias que afectan de una manera muy específica y directa a nuestra Comunidad Autónoma:

a) Dos de ellas tienen su origen en sendas cuestiones de inconstitucionalidad (las núms. 2560-2019 y 2561-2019), elevadas al Alto Tribunal por la Sección Primera de la Sala de lo Contencioso-Administrativo del Tribunal Superior de Justicia de Extremadura, con un objeto idéntico: la expresión de las dudas de este órgano jurisdiccional con respecto al ajuste con nuestra Carta Magna de dos preceptos legales autonómicos, como son, en primer término, el art. 11.3.1 b), párrafo segundo, de la Ley 15/2001, de 14 de diciembre, del Suelo y Ordenación Territorial de 
Extremadura -en la redacción dada a este precepto por la Ley autonómica 9/2011, de 29 de marzo-, y, en segundo término, por la disposición adicional única de esta última norma legal dictada por la Asamblea de Extremadura en el año 2011. Estas dos resoluciones constitucionales se enmarcan dentro del largo conflicto jurídico que afecta a la ordenación urbanística de los terrenos de una isla en el embalse de Valdecañas (río Tajo).

b) La tercera Sentencia enjuicia un recurso de amparo parlamentario promovido, sobre la base del art. 42 de la Ley Orgánica del Tribunal Constitucional de 1979, por un miembro de la Asamblea de Extremadura contra diversos acuerdos de la mesa de este Parlamento autonómico por los que se le atribuye la condición de diputado no adscrito y se fijan los derechos que en cuanto a tal categoría representativa le corresponden.

5.2.2. Las resoluciones constitucionales que afectan a la reordenación legal de los terrenos comprendidos en la isla del embalse de Vadecañas

a) La resolución clave en este ámbito es la STC 134/2019, de 13 de noviembre, que estima parcialmente la cuestión de inconstitucionalidad núm. 2560-2019. Esta Sentencia del Pleno del Alto Tribunal tiene como Ponente al Magistrado D. Antonio Narváez Rodríguez, contando con el voto particular discrepante del Magistrado D. Ricardo Enríquez Sancho.

La repercusión de esta Sentencia para nuestra región es enorme, dado que se integra - como ya hemos avanzado- en un viejo conflicto de naturaleza urbanística propiciado por la adopción en abril de 2007 de un Decreto por parte de la Junta de Extremadura mediante el que se aprobaba definitivamente un Proyecto de Interés Regional (PIR) con el objetivo de recalificar y ordenar los terrenos de una isla en el embalse de Valdecañas (río Tajo) para la construcción de un complejo residencial de lujo. Este Decreto fue anulado, en primera instancia, mediante las Sentencias 195 y 196, de 9 de marzo de 2011, de la Sala de lo ContenciosoAdministrativo del Tribunal Superior de Justicia de Extremadura, 
resultando confirmadas ambas resoluciones en casación por sendas Sentencias de 21 de enero de 2014, de la Sala Tercera del Tribunal Supremo. A pesar de la vetustez de todas estas resoluciones judiciales, lo cierto es que sus amplísimas repercusiones de naturaleza tanto económica como medioambiental han impedido (al menos hasta ahora) su ejecución, que conllevaría la reposición de los terrenos de la isla a la situación anterior a la materialización del proyecto, tras el costosísimo derribo de la urbanización.

En este contexto fáctico y jurídico, el Tribunal Constitucional se enfrentó a la cuestión de inconstitucionalidad núm. 2560-2019, elevada por la Sección Primera de la Sala de lo Contencioso-Administrativo del Tribunal Superior de Justicia de Extremadura, en relación con dos preceptos legales aprobados por la Asamblea de Extremadura en el año 2011 con el fin de regularizar la situación urbanística de la isla de Valdecañas, tras la notificación de las referidas Sentencias del órgano jurisdiccional extremeño.

En la STC 134/2019 ahora reseñada, nuestro más Alto Tribunal declara: $1^{\circ}$ ) Por un lado, la inconstitucionalidad (y nulidad) del art. 11.3.1 b), párrafo segundo, de la vieja Ley del Suelo y Ordenación Territorial de Extremadura de 2001 -en la redacción dada a este precepto por el artículo único de la Ley 9/2011, de 29 de marzo-, por resultar contrario a las previsiones básicas estatales en la materia con infracción mediata de las reglas $1^{\mathrm{a}}$ y $23^{\mathrm{a}}$ del apartado primero del art. $149 \mathrm{CE}$, en la medida en que el Legislador autonómico no puede dictar una norma que permita la transformación urbanística de terrenos incluidos en la Red Natura 2000 dada su especial protección medioambiental. Para comprender la repercusión de este pronunciamiento, debe tenerse en cuenta que los terrenos de la isla de Valdecañas están dentro de esta Red y su transformación urbanística para la construcción de un complejo residencial es evidente; $2^{\circ}$ ) Por otro lado, se desestima la eventual inconstitucionalidad de la disposición adicional única de la meritada Ley 9/2011, que establece un procedimiento de homologación de los instrumentos urbanísticos y de 
ordenación del territorio ya existentes para ajustarlos a la nueva legalidad rectora de ambas materias. Considera el Tribunal Constitucional a este respecto que esta segunda norma cuestionada no constituye una ley singular mediante la que se pretenda eludir la ejecución de las meritadas Sentencias de 9 de marzo de 2011 del Tribunal Superior de Justicia extremeño, ya que, al referirse, "en abstracto", a los instrumentos de "ordenación del territorio y de ordenación urbanística vigentes a la fecha de entrada en vigor de esta Ley", "no se trata de una norma dictada en atención a un supuesto de hecho concreto y singular que agote su contenido y eficacia” en el PIR de la isla de Valdecañas. Sobre esta base, concluye la Sentencia reseñada "que, más allá de un juicio de intenciones sobre los móviles del Legislador autonómico, que no nos corresponde valorar (...), y de que los actos de homologación serán ilegítimos si son el resultado de la aplicación de preceptos inconstitucionales y, por consiguiente, anulados por este Tribunal (...), la disposición adicional única de la Ley 9/2011 no vulnera los arts. 24.1, 117 y 118 CE”.

b) El contenido de la Sentencia constitucional 152/2019, de 25 de noviembre, es absolutamente tributario de la STC 134/2019. Esta segunda resolución que afecta a la normativa legal de reordenación de los terrenos de la isla de Valdecañas es mera aplicación de doctrina jurídica anterior, lo que justifica que haya sido dictada por la Sala Segunda del Alto Tribunal, habiendo contado como ponente con el Magistrado D. Pedro José González-Trevijano Sánchez.

El fallo de este pronunciamiento es doble: $1^{0}$ ) Por un lado, se declara extinguida por pérdida sobrevenida de objeto la cuestión de inconstitucionalidad núm. 2561-2019 en relación con el art. 11.3.1b), párrafo segundo, de la Ley 15/2001, de 14 de diciembre, del Suelo y Ordenación Territorial de Extremadura -en la redacción dada a este precepto por la Ley autonómica 9/2011, de 29 de marzo-. Recordemos que este precepto ya había sido declarado inconstitucional y nulo por la STC 134/2019, quedando, por tanto, expulsado de nuestro ordenamiento jurídico y “disipada la duda planteada" [FJ 3 a)]. Y $2^{\circ}$ ) Por otro lado, se desestima la 
impugnación de la disposición adicional única de la referida Ley 9/2011 mediante una mera remisión al FJ 5 de la STC 134/2019 en la medida en que existía una coincidencia objetiva en cuanto a los contenidos de las cuestiones de inconstitucionalidad núms. 2560 y 2561 del año 2019.

5.2.3. La novedosa doctrina constitucional sobre los diputados no adscritos que tiene su origen en un recurso de amparo parlamentario formulado desde Extremadura

La STC 159/2019, de 12 de diciembre, declara la vulneración del derecho fundamental de un antiguo diputado del grupo popular (D. Juan Antonio Morales Álvarez), que abandonó esta formación adquiriendo la condición de no adscrito, "a ejercer las funciones representativas con los requisitos que señalan las leyes (art. 23.2 CE)” por diversos acuerdos de la mesa de la Asamblea de Extremadura "en la medida que privan en términos absolutos al demandante del derecho a formular propuestas de pronunciamiento en pleno" (apartado primero del fallo).

Esta resolución fue dictada por el Pleno del Tribunal Constitucional, al ser avocado el recurso de amparo a este órgano, siendo ponente el Presidente del Alto Tribunal, el Magistrado D. Juan José González Rivas.

La importancia de esta Sentencia constitucional radica en su novedad, puesto que sirve para perfilar los derechos de los diputados no adscritos a ningún grupo parlamentario en una cámara legislativa. En este contexto, la doctrina fundamental recogida en la misma puede sintetizarse en los siguientes términos:

$\left.1^{\mathrm{o}}\right) \mathrm{El}$ art. 23.2 $\mathrm{CE}$ reconoce el derecho fundamental al acceso, a la permanencia y al ejercicio de cargos públicos de naturaleza representativa por parte de los ciudadanos. Este derecho fundamental de los representantes de los ciudadanos a ejercer su cargo está en estrecha conexión con el derecho fundamental de estos últimos a participar en los asuntos públicos a través, precisamente, de representantes libremente elegidos 
en elecciones periódicas por sufragio universal recogido en el art. 23.1 CE [FJ 5 a)].

$2^{\circ}$ ) El derecho fundamental de acceso a los cargos públicos es "un derecho de configuración legal” cuyo núcleo fundamental está constituido, esencialmente, por las facultades directamente relacionadas con el ejercicio de las potestades legislativas, por un lado, y de control al gobierno, por otro [FJ 5 b) y c)].

$3^{\circ}$ ) No forman parte, sin embargo, del núcleo esencial o central de la función representativa los derechos de contenido económico como son las retribuciones o el mantenimiento del régimen de dedicación exclusiva de los diputados no adscritos (FJ 6).

$4^{\circ}$ ) La existencia de la figura del diputado no adscrito no es lesiva del derecho fundamental al ejercicio del cargo público representativo ("ius in officium") (FJ 8).

$5^{\circ}$ ) Corresponde a la mesa de la Asamblea de Extremadura acordar las facultades de intervención del diputado no adscrito en los ámbitos tanto de la producción normativa como del control gubernamental. Para el ejercicio de esta función la mesa se encuentra vinculada por aquellos principios y reglas previstos en el reglamento de la cámara legislativa (FFJJ 9 y 11).

$6^{\circ}$ ) El Reglamento de la Asamblea de Extremadura ha previsto en su art. 39.5 que las facultades de intervención de los diputados no adscritos en el ejercicio de su función representativa se corresponden con "los derechos reconocidos reglamentariamente a los diputados considerados de forma individual”. Este precepto se ajusta plenamente, según nuestro Tribunal Constitucional, al art. 23.2 CE, debiendo tenerse en cuenta que el precepto del reglamento parlamentario "cierra el paso a una excesiva representación del diputado no adscrito". Y es que esta cláusula, en efecto, "asegura al diputado no adscrito los derechos inherentes a la condición de cargo público que son 'reconocidos reglamentariamente a los 
diputados considerados de forma individual', pero al mismo tiempo le impide que, beneficiándose de su situación de diputado individual y no inserto en ningún grupo político, por haber abandonado el grupo parlamentario del que formaba parte, pase a gozar de una injustificada posición preponderante en perjuicio del resto de diputados que, por integrarse en grupos políticos, ven racionalizado el ejercicio de ciertas funciones inherentes al núcleo de la función representativa” (FJ 10). En definitiva, el referido precepto del reglamento parlamentario extremeño "es plenamente constitucional porque neutraliza la desigualdad en el ejercicio de la función representativa que llevaría aparejada la sobrerrepresentación del diputado no adscrito" (FJ 12).

$7^{\circ}$ ) Una cosa es que las previsiones del art. 39.5 del Reglamento de la Asamblea de Extremadura respeten el art. 23.2 CE y otra cosa diferente es que resulten constitucionales, en todo caso, las aplicaciones que la mesa de este Parlamento autonómico haga mediante sus correspondientes acuerdos. Pues bien, en el enjuiciamiento que el Tribunal Constitucional efectúe de cada uno de los acuerdos de la mesa de la Asamblea aplicativos del reglamento parlamentario debe tenerse en consideración "la especial relevancia de la autonomía parlamentaria y, como consecuencia de ello, la facultad que la Constitución reserva a las cámaras de establecer, interpretar y aplicar las normas que rigen su organización y funcionamiento, pues la ordenación reglamentaria goza de amplia libertad de configuración, siempre que se respete el derecho de los parlamentarios con la representación política” (FJ 12).

$8^{\circ}$ ) A partir de esta doctrina general, el Tribunal Constitucional enjuicia de manera particularizada las quejas constitucionales del demandante de amparo sobre los acuerdos de la mesa de la Asamblea de Extremadura en relación con el ejercicio de sus funciones representativas en tanto que diputado no adscrito, llegando a las siguientes conclusiones desestimatorias de la mayor parte de sus pretensiones: 
i) Considera el Alto Tribunal, en primer lugar, que la queja contenida en la concreta demanda de amparo parlamentario sobre el cupo señalado para el diputado no adscrito por la mesa de la Asamblea de Extremadura para las interpelaciones y las preguntas al gobierno autonómico, tanto en los plenos parlamentarios como en las comisiones, debe ser desestimada, porque la mesa aporta en sus acuerdos una justificación razonable, mientras que la demanda de amparo no argumenta en modo alguno que dicho "cupo sea desproporcionado o sea de alguna manera inferior al que corresponde a los diputados individualmente considerados" [FJ 12 a)], sin que corresponda a nuestro Guardián de la Constitución reconstruir de oficio las demandas de amparo, supliendo las razones no expuestas por las partes.

ii) El Tribunal Constitucional desestima, en segundo lugar, la queja de amparo del diputado no adscrito recurrente referida a la privación del uso de la palabra en algunos debates plenarios (en el caso concreto, los de totalidad, los de convalidación de los decretos-leyes y los relativos a las propuestas de impulso y a las de pronunciamiento en pleno), porque, ante la justificación de este acuerdo por la mesa de la Asamblea de Extremadura, "no consta en el escrito rector de este proceso un razonamiento que argumentase, teniendo en cuenta todas estas circunstancias de contexto, que la privación del uso de la palabra en esos tres tipos de debates plenarios [le] somete a una posición de infrarrepresentación respecto del resto de diputados, por lo que, de acuerdo a la mencionada doctrina constitucional según la que no ha lugar a que este Tribunal reconstruya de oficio las demandas de amparo (...), esta tercera y última queja debe ser desestimada" [FJ 12 c)].

iii) El Alto Tribunal descarta, en tercer lugar, que se haya producido una lesión de los derechos fundamentales del recurrente al verse excluido de manera absoluta de la presentación de propuestas de impulso, porque, por un lado, la exigencia del "visto bueno del portavoz" para el ejercicio de este tipo de iniciativas parlamentarias "no es un mero requisito formal, sino una previsión sustantiva, en virtud de la que se sustrae 
este tipo de iniciativa del acervo de actuaciones parlamentarias que se reconocen reglamentariamente al diputado considerado individualmente"; y, por otro, "y teniendo presente que el diputado no adscrito tiene a su disposición otros medios de control al Gobierno (interpelaciones, preguntas, etc.), la privación de este tipo de iniciativas no le coloca automáticamente en una situación de desigualdad desproporcionada respecto del resto de diputados, no pudiendo este Tribunal hacer en este caso una ponderación más incisiva porque falta en el escrito rector de este proceso una argumentación concreta en este sentido" [FJ 12 b)].

$9^{\circ}$ ) Como contraste al rechazo de estas quejas de amparo, el Tribunal Constitucional estima la referida a que la prohibición absoluta de formulación de propuestas de pronunciamiento en pleno decretada por la mesa de la Asamblea de Extremadura vulnera el derecho fundamental al ejercicio de la función representativa del diputado no adscrito demandante de amparo. Concluye, en este sentido, la mayoría del Alto Tribunal (con la opinión contraria del voto particular disidente formulado por el Magistrado D. Andrés Ollero Tassara) que: "En consecuencia, la mesa, en la medida que en los acuerdos impugnados niega que el recurrente pueda presentar propuestas de pronunciamiento en pleno, le está privando de facultades que, además de ser inherentes a la función representativa, aparecen reconocidas en el reglamento parlamentario a los diputados considerados en forma individual y, por tanto, atribuidas al diputado no adscrito por el art. 39.5 del Reglamento" [FJ 12 b)].

\section{A PROPÓSITO DE ALGÚN PROBLEMA CRÓNICO EN LA REGIÓN: LA DEFICITARIA RED EXTREMEÑA DE INFRAESTRUCTURAS}

Las deficiencias que Extremadura padece en relación con la red de transportes que conectan a la región con el exterior, pero también entre sus municipios y provincias, constituyen un problema serio que raya la cronificación tanto por la inoperatividad de las soluciones que se 
proponen como por los males que aquejan a la Comunidad, materializados en un escaso desarrollo socioeconómico de la sociedad extremeña, y que, sin duda, están asociados precisamente a esta deficitaria red de infraestructuras. A los males que acusan los trenes que pasan por la región hay que añadir las disyuntivas que se están planteando sobre el trazado, o la ejecución en su caso, de importantes autovías que unirían, una, el oeste con el levante español, otra, las capitales de las dos provincias de la región; y a este panorama ha venido a sumarse también el funcionamiento irregular del único aeropuerto con que cuenta la Comunidad $\mathrm{Au}-$ tónoma motivado por problemas de visibilidad a causa de las frecuentes nieblas que, durante una parte del año, cubren los terrenos donde se encuentra ubicada esta infraestructura.

\subsection{EL CAOS FERROVIARIO}

La caótica situación de las infraestructuras ferroviarias en Extremadura resulta bien conocida para la sociedad regional, que la padece desde hace muchos años. La novedad con la que nos encontramos en los primeros días de enero de 2019 radicó en que, por primera vez, los medios de comunicación nacionales y las redes sociales decidieron hacerse eco durante toda una semana de la vida cotidiana de los viajeros extremeños, que a veces no pueden esquivar el tren para viajar. Y eso, a pesar de que los trescientos kilómetros que separan Cáceres de Madrid se recorren en cuatro horas y los cuatrocientos entre Badajoz y Madrid se hacen en seis.

Extremadura cuenta con 41.634 kilómetros cuadrados de extensión, sin embargo, sólo dispone de 725 kilómetros de vías férreas, todos ellos de vía única, carentes por completo de electrificación y sin un solo servicio de larga distancia. La cantidad de promesas incumplidas por los políticos de todos los colores en relación con las mejoras ferroviarias que nunca llegan contrasta con la situación actual de necesidad real de mejorar el estado de las infraestructuras ferroviarias en Extremadura como vía de desarrollo socioeconómico regional. 
La crisis no ha permitido ir a una mayor velocidad en su construcción y los gobiernos competentes han decidido priorizar la puesta en marcha de otros trayectos que, al fin y al cabo, unen a núcleos de población mayores. La decisión portuguesa de paralizar el desarrollo de la alta velocidad hace unos años, cuando la crisis empezó a asolar el país vecino y amigo, tampoco ha ayudado mucho: la conexión ferroviaria entre Madrid y Lisboa, pasando por las capitales extremeñas, dejó de tener interés real. Hasta marzo del 2016 no hubo una mínima reacción política en la región, y tampoco fue mucho mayor la reacción de los grupos sociales más o menos organizados de nuestro territorio. En esta fecha, la Junta de Extremadura, dirigida por el PSOE, firmó con los sindicatos mayoritarios de la región (UGT y CCOO) y con la Confederación Regional Empresarial (CREEX) un Pacto Social y Político por el Ferrocarril en Extremadura, para reclamar al Gobierno central, presidido por Mariano Rajoy, el desarrollo de las infraestructuras ferroviarias de la Comunidad Autónoma. En el mes de mayo siguiente, todos los grupos políticos con representación parlamentaria en la Asamblea de Extremadura (PSOE, PP, Podemos y Ciudadanos) firmaron también un Pacto Político que se adhirió a las reivindicaciones del anterior Pacto Social. Otras fuerzas y plataformas ciudadanas lo harían en las siguientes semanas. Los movimientos ciudadanos también organizaron plataformas reivindicativas: la más conocida es, sin duda, "Milana Bonita", que, rememorando a los personajes de la novela de Miguel Delibes "Los Santos Inocentes", ha contribuido de manera impagable a dar a conocer, a través de sus caracterizaciones y "performances”, las penurias del ferrocarril extremeño.

A partir de estos mimbres se celebró el día 18 de noviembre de 2017 una concentración de carácter lúdico, además de reivindicativo, en la capital de España bajo el lema "Por un tren digno ya”, que congregó a varias decenas de miles de personas (más de cuarenta mil, según el gobierno regional), llegados desde Extremadura, pero también de otras partes del país, y con una importante representación castellano-manchega (pues Talavera de la Reina y su entorno sufren también las condiciones 
penosas del ferrocarril hacia nuestra región). Las reivindicaciones, según se expresó en el manifiesto consensuado entonces por los partidos políticos, los agentes sociales y las administraciones públicas extremeñas, se focalizaron en tres puntos principales: la urgencia de la puesta en marcha de la línea de alta velocidad entre Madrid, Badajoz y la frontera portuguesa; la modernización de la red convencional; y la puesta a disposición de los extremeños de una red moderna de comunicaciones en el interior de la región.

Esta manifestación se volvió a organizar el 18 de noviembre de 2018 en Cáceres, reuniendo a unas veinticinco mil personas según la organización (a unas quince mil en las cifras ofrecidas por la Delegación del Gobierno en la Comunidad Autónoma). El día anterior el Partido Popular extremeño, partidario de repetir las protestas en Madrid, había convocado, asimismo, una concentración reivindicativa por un tren digno para nuestra región en la capital de España, dado que su máximo dirigente sostenía que "las voces resuenan más en Madrid”. Sin embargo, la propuesta de alzar las voces de los extremeños ante el Gobierno central, entonces presidido por el socialista Pedro Sánchez, no tuvieron eco y la manifestación en la capital de España no tuvo lugar.

Durante esos últimos días de noviembre salió a la luz otra noticia, no obstante, muy inquietante para los intereses regionales: el Primer Ministro luso, D. Antonio Costa, expresaba ante la prensa sus dudas sobre la necesidad de que la conexión ferroviaria de alta velocidad entre España y Portugal se hiciese por Extremadura. Nuestra región ya había visto cómo años antes, en concreto en verano de 2012, se había desplazado la conexión ferroviaria directa entre Madrid y Lisboa, a través del tren Lusitania, a la vecina Comunidad Autónoma de Castilla y León. Para incrementar todavía más la creciente preocupación de una buena parte de la sociedad extremeña, esta cuestión no fue ni siquiera abordada en la XXX Cumbre Hispano-Portuguesa celebrada en Valladolid el 21 de noviembre de 2018. 
En 2019, el nivel de reivindicación social sobre esta cuestión se ha ido diluyendo de manera tal que, poco a poco, han dejado de ser noticia de portada los incidentes ferroviarios, quizá porque puedan haber disminuido, para dar paso a notas informativas sobre los avances en la construcción de las infraestructuras ferroviarias. Esta pérdida de interés y actualidad se ha hecho patente con la ausencia de convocatoria este año de la manifestación reivindicativa que se convocaba cada 18 de noviembre desde 2017, gracias al apoyo de todas las instituciones extremeñas, de los partidos políticos más significativos de la región y de amplísimos colectivos sociales, y que contaba con un grandísimo número de asistentes, sobre todo si se tienen en cuenta los reducidos índices poblacionales extremeños. Un silencio que contrasta con la confirmación por parte del Ministerio de Fomento de que los plazos no se van a cumplir y de que habrá un nuevo retraso de dos años.

Esta es la historia del AVE extremeño, una sucesión de plazos que no se cumplen, de fechas que se posponen, de compromisos que caen en el olvido. El pasado mes de junio se adjudicó el primer contrato para la electrificación de la vía del tren en Extremadura. El proyecto completo de electrificación que debería estar listo en 2020 ya ha sido aplazado hasta 2021. Suma y sigue. Y mientras, Extremadura sigue siendo la única Comunidad Autónoma de España sin un solo kilómetro de vía sin electrificar.

Si así está la situación con respecto a la alta velocidad ferroviaria, las cosas tampoco parece que hayan avanzado mucho en relación con el desarrollo del llamado Corredor Atlántico, en el que Extremadura tiene un particular interés.

\subsection{LAS CARENCIAS DE LA RED DE CARRETERAS}

Las ciudades de Cáceres y Badajoz son de las pocas capitales de provincia en España que no están unidas por una autovía directa. La 
iniciativa de reconvertir la carretera regional (la Ex-100), que en la actualidad conecta ambas poblaciones, data de 2006, año en el que la Junta de Extremadura puso en marcha los trámites administrativos. Se plantearon entonces hasta tres corredores distintos; se llegó a elegir el mejor trazado en el año 2008 (aquel que discurre junto a la actual Ex-10o); y en marzo de 2009 se publicó oficialmente la declaración de impacto ambiental (DIA) favorable y se aprobaron los proyectos de sus cuatro tramos. A finales de ese año 2009, la Junta de Extremadura y el Ministerio de Fomento firmaron un convenio por el que este último asumiría el coste de la obra que, una vez concluida, pasaría a formar parte de la Red de Carreteras del Estado.

La crisis económica y, con ello, la falta de financiación ha servido de justificación para la inejecución de esta infraestructura "necesaria e importante", según la Junta de Extremadura, que la ha incluido en el Plan Plurianual de Infraestructuras 2016-2030. Pero, aunque sin fijar plazos por aquello de no incumplirlos, en este 2019 el Gobierno regional ha dado el primer paso para poner en marcha una obra de poco más de 87 kilómetros que no tiene fecha ni de inicio ni de final (aunque se baraja que comience en 2020, nadie se atreve a concretar fechas). En efecto, en abril de 2019, se publicaba en el Boletín Oficial del Estado y en el Diario Oficial de Extremadura el acuerdo de cambio de titularidad de la carretera Ex-10o (Cáceres-Badajoz), hasta entonces perteneciente a la Junta de Extremadura, a favor del Ministerio de Fomento, aprobado posteriormente en el Consejo de Ministros y en el Consejo de Gobierno regional (Real Decreto 334/2019, de 26 de abril, y Decreto 44/2019, de 23 de abril). Este traspaso supone que la futura autovía ya no se llamará ExA4, y consiguientemente no formará parte del catálogo de la Red de Carreteras de Extremadura. La carretera pertenece ya al Ministerio de Fomento, recobrando su nombre primigenio de $\mathrm{N}-523$, y su denominación final será A-58, quedando integrada en la autovía que une Trujillo y Cáceres que ahora tendrá como destino final Badajoz. Y sobre el Ministerio 
de Fomento recae ahora la responsabilidad de hacer realidad la ansiada autovía entre Cáceres y Badajoz.

El proyecto de autovía que conectará el Atlántico con el Mediterráneo (y que supondrá un eje peninsular Valencia-Lisboa), es otro de los corredores que lleva también más de una década paralizado. Esta Autovía del Levante (que unirá la ciudad más poblada de nuestra región, Badajoz, con Valencia a través de Castilla-La Mancha) tiene pendiente la conexión entre Mérida y Ciudad Real. En esta ocasión, la ausencia de avances en el proyecto de convertir la $\mathrm{N}-430$ en autovía para enlazar en el último tramo con la A-43 obedece a la falta de acuerdo para elegir el mejor trazado, motivado por la discordia latente entre los municipios que pueden verse afectados. Las alternativas sobre el recorrido de la vía son dos: por el norte, atravesando la comarca de La Siberia para llegar a Ciudad Real, y que es la solución que demandan los municipios lindantes de una carretera congestionada por el tráfico pesado a la ciudad manchega; o, por el sur, discurriendo por La Serena hasta conectar con la autovía A-41 en las proximidades de Puertollano, y cuyo trazado mejoraría la conectividad y daría servicio a una zona deprimida. El avance de la despoblación, el desempleo, etc., son otros de los argumentos que esgrimen las partes para resolver una disyuntiva que nadie quiere afrontar de una forma seria y racional.

El posible enfrentamiento que puede generarse entre las diferentes poblaciones afectadas ha llevado al Ejecutivo autonómico a eludir, en efecto, cualquier posicionamiento y a evitar toda declaración a favor de alguna de las dos opciones. Por el contrario, la Junta de Extremadura ha manifestado que la elección del trazado definitivo se hará "en la mesa del Gobierno de España”, y que el Gobierno regional "velará por el interés general, que es como se tienen que tomar las decisiones cuando no van a gustar a todas las partes implicadas" (en palabras textuales de $\mathrm{D}^{\mathrm{a}}$. Isabel Gil Rosiña, portavoz de la Junta de Extremadura). Ya sea por el interés general, ya por echar balones fuera, el caso es que la decisión final sobre el trazado de la infraestructura se ha traspasado al Gobierno central que 
deberá ser quien se decante por una u otra opción. Y en este sentido, el Ministro de Fomento, D. José Luis Ábalos, ya ha manifestado que la solución será pactada entre el Gobierno de la Nación y las dos Comunidades Autónomas implicadas. Parecen acrecentarse así las dificultades para salvar la dicotomía de la elección del mejor trazado y superar las luchas territoriales y comarcales. Aquí solo hemos contado las de la región extremeña, imaginamos que la Comunidad castellano-manchega no está exenta de tener que explicar y justificar la elección de la alternativa más conveniente para los intereses de la provincia de Ciudad Real y de la región.

Mejorar la movilidad, la conectividad y la comunicación de los municipios de la región, es, sin duda, de interés general, como también es de general interés velar por que no se produzca el aislamiento de ninguna comarca o contribuir al desarrollo socioeconómico de todo el territorio de la región. No es extraño que se proponga como tercera opción la posibilidad de construir dos infraestructuras distintas, con la conformación de una “y” griega, con la finalidad de conectar las dos vías. Sí sorprende, sin embargo, la poca determinación y el poco arrojo de los responsables políticos, sin ninguna altura de miras, incapaces de discriminar que la solución óptima es realizar la autovía.

\subsection{LAS DEFICIENCIAS EN EL TRÁFICO AÉREO}

La "nueva etapa" del Aeropuerto de Badajoz, que arrancó en octubre 2018 (con una operatividad bajo la fórmula de Obligación de Servicio Público-OSP-), no ha estado exenta de incidentes. Las noticias sobre la cancelación de servicios, tanto de despegue como de aterrizaje de vuelos, o de su desvío (con el desplazamiento de los viajeros hasta Sevilla en autobús para coger un avión que los llevara a sus destinos o desde la capital andaluza hasta alcanzar su destino en Badajoz) por cuestiones meteorológicas (bancos de niebla) se han sucedido en los inicios y en el final del año 2019, sin que se atisbe ningún remedio en el horizonte. 
El hecho de que los vuelos desde Badajoz a Madrid y Barcelona tengan la categoría de OSP ha supuesto la mejora de precios y de horarios posibilitando ir y volver a ambas ciudades en el mismo día. De esta forma, el avión se ha convertido en una alternativa para viajar desde y hacia la Comunidad Autónoma. Los datos confirman el buen momento del aeropuerto extremeño. Según AENA, la empresa pública que gestiona los aeropuertos españoles, durante el año 2019 han pasado por las instalaciones del aeródromo de Badajoz la cifra de 75.418 pasajeros, esto es, un $44,8 \%$ más respecto al mismo periodo del año anterior.

Estos datos contrastan, sin embargo, con las continuas noticias a propósito de retrasos de los vuelos debido a las intensas nieblas. Una demoras que ya han hecho alzar la voz a colectivos (como la Conferencia Regional Empresarial Extremeña, CREEX) y formaciones políticas denunciando que estas incidencias repercuten negativamente sobre el buen funcionamiento y evolución del aeródromo pacense, y pidiendo, en consecuencia, soluciones. En este sentido, se reclama un sistema antiniebla más adecuado (como el que ya existe en otros aeropuertos nacionales) para que los aviones puedan aterrizar y despegar cuando acontezca este fenómeno meteorológico tan frecuente en esa parte del territorio extremeño. Desde el Gobierno regional se ha planteado cambiar los horarios en el periodo de mayor niebla, esto es, los meses de diciembre y enero, para que los vuelos del aeropuerto "salgan a horas en las que la niebla haya levantado".

\section{A MODO DE BREVE CONCLUSIÓN}

Sea como fuere, los problemas de la región con todos los tipos de transporte y, con ello, las dificultades de los extremeños para desplazarse, no cesan. En este contexto, la conclusión general que cabe extraer de la precaria situación en la que se encuentran las redes de comunicación regionales se concreta en una insoportable levedad de la incertidumbre. $\mathrm{Y}$ es que, si bien es cierto que construir infraestructuras lleva años, también 
lo es que la sociedad extremeña (como cualquier sociedad) se merece saber, y de una vez por todas de verdad, en qué situación se encuentran las obras que efectivamente se hayan planificado, o que se estén ejecutando en su caso, cómo se van a ir desarrollando y cuándo van a terminar (mes arriba o mes abajo, y no una década arriba o una década abajo, que es la medida en la que se manejan las previsiones para nuestra región ya desde el siglo pasado).

Vicente Álvarez García Área de Derecho Administrativo Departamento de Derecho Público Universidad de Extremadura Av. Universidad, s/n. 10003 - Cáceres vjalvarez@unex.es https://orcid.org/oooo-0003-1979-603X

Flor Arias Aparicio Área de Derecho Administrativo Departamento de Derecho Público

Universidad de Extremadura Av. Universidad, s/n. 10003 - Cáceres florarias@unex.es https://orcid.org/oooo-0002-9822-8905

Enrique Hernández Díez Área de Derecho Administrativo Departamento de Derecho Público Universidad de Extremadura Av. Universidad, $\mathrm{s} / \mathrm{n}$. 10003 - Cáceres ehernandezdiez@unex.es https://orcid.org/oooo-0003-3112-8704 